\title{
1 A developmental perspective on the evolution of the nervous system
}

2

3 José M. Martín-Durán ${ }^{1,2^{*}}$, Andreas Hejnol ${ }^{1 *}$

4

$5 \quad{ }^{1}$ Sars International Centre for Marine Molecular Biology, University of Bergen.

6 Thørmohlensgate 55, 5006 Bergen. Norway

$7 \quad{ }^{2}$ School of Biological and Chemical Sciences, Queen Mary University of London. Mile

8 End Road. E1 4NS London. United Kingdom

9

10 *Corresponding authors (andreas.hejnol@uib.no, chema.martin@qmul.ac.uk)

11

12 


\section{Abstract}

14 The evolution of nervous systems in animals has always fascinated biologists, and thus

15 multiple evolutionary scenarios have been proposed to explain the appearance of

16 neurons and complex neuronal centers. However, the absence of a robust phylogenetic

17 framework for animal interrelationships, the lack of a mechanistic understanding of

18 development, and a recapitulative view of animal ontogeny have traditionally limited

19 these scenarios. Only recently, the integration of advanced molecular and

20 morphological studies in a broad range of animals has allowed tracing the evolution of

21 developmental and neuronal characters on a better-resolved animal phylogeny. This has

22 falsified most traditional scenarios for nervous system evolution, paving the way for the

23 emergence of new testable hypotheses. Here we summarize recent progress in studies of

24 nervous system development in major animal lineages and formulate some of the

25 arising questions. In particular, we focus on how lineage analyses of nervous system

26 development and a comparative study of the expression of neural-related genes has

27 influenced our understanding of the evolution of an elaborated central nervous system

28 in Bilateria. We argue that a phylogeny-guided study of neural development combining

29 thorough descriptive and functional analyses is key to establish more robust scenarios

30 for the origin and evolution of animal nervous systems.

\section{Keywords}

33 Nervous system, evolution, homology, blastopore, fate map, gene expression. 


\section{Introduction}

The nervous system is the set of cells, tissues and organs involved in perceiving and elaborating adequate responses to internal and external stimuli in animals (SchmidtRhaesa, 2007). As such, it is responsible for most animal behaviors, from simple directed muscular movements to abstract reasoning. Therefore, understanding how this organ system evolved and acquired the degree of sophistication displayed in many extant animals has been one of the most alluring questions in Biology. Despite the many advances in neurobiology, physiology, developmental and cell biology on this matter, unraveling the evolutionary history of the nervous system is still contentious (Arendt and Nübler-Jung, 1994, 1999; Arendt et al., 2016; Hejnol and Lowe, 2015; Holland et al., 2013; Holland, 2003; Lowe et al., 2006; Lowe et al., 2003; Northcutt, 2012; Pani et al., 2012; Tosches and Arendt, 2013). This is partially because animal phylogeny, and in particular the deepest nodes of the animal tree of life are debated (Dunn et al., 2008; Hejnol et al., 2009; Moroz et al., 2014; Ryan et al., 2013; Simion et al., 2017; Whelan et al., 2015) thus muddling our capacity to discern the primary origins of the nervous system (Jekely et al., 2015; Liebeskind et al., 2016; Moroz et al., 2014; Ryan, 2014). At the same time, most studies in nervous system development have focused on a handful of animal lineages, which has biased and limited our interpretation of how the nervous system diversified (Hejnol and Lowe, 2015). Herein, we review how the current status in animal phylogeny and the recent investigation of previously neglected animal taxa impact our understanding of the intricate story of the nervous system. We use these insights to evaluate very early ideas about the evolution of complex animal nervous systems and provide an updated developmental perspective. We focus this manuscript on the evolution of the central nervous system (CNS), which we define as the accumulation of neurons and axons usually positioned deep in the body and more or 
less dissociated from more diffuse nerves and neurons that remain in connection with the body wall (i.e. the peripheral nervous system or PNS) (Bullock and Horridge, 1965; Schmidt-Rhaesa, 2007). Typically, the CNS consists of an anterior condensation, or brain, and one or more longitudinal nerve cords. We conclude this review by putting forward future lines of research that might contribute to elucidate disputed aspects of neural evolution.

\section{Traditional scenarios for bilaterian nervous system evolution}

Markedly narrative, traditional evolutionary scenarios aimed at delivering plausible explanations for the origin and diversification of animal morphology (e.g. the diversity of neural arrangements), while at the same time were used to define phylogenetic relationships among animal lineages. This inevitably led to circular reasoning (e.g. an animal lineage was placed in the phylogeny based on their morphology, and at the same time their given phylogenetic position was used to justify their morphology and evolution of a specific character), and endless debates between the advocates (see i.e. Dougherty, 1963). In most of the cases, these scenarios focused on defining linear transformations of adult body plans, with developmental biology only playing a minor role. When embryos were considered, the argumentation was strongly influenced by Haeckel's ‘biogenetic law’ (Haeckel, 1866), namely that ontogeny (i.e. development) is a fast recapitulation of phylogeny. Embryos were not yet seen adaptive and evolvable, but as mirrors of ancient adult forms that existed once in the past, which were figuratively named after their corresponding developmental stage (e.g. 'Blastaea' and 'Gastraea'). As we illustrate below with Reisinger's 'orthogon'-scenario (Reisinger, 1925), Sedgewick’s and Balfour's ‘oral nerve ring’ scenario (Balfour, 1883; Sedgwick, 1884) and the 'nemertean' and 'annelid' scenarios by Hubrecht (Hubrecht, 1883, 1887) 
and Dohrn (Dohrn, 1875) respectively, traditional scenarios proposed alternative evolutionary transformations to explain the emergence of condensed neural cords from a diffuse ectodermal nerve net composed out of basiepidermal interconnected neurons (Hejnol and Rentzsch, 2015).

\section{The 'orthogon' scenario}

An orthogonal nervous system is defined by multiple pairs of longitudinal cords distributed along the dorsoventral axis of the animal and connected with transverse commissures (Richter et al., 2010). Such nervous system architecture is mainly present in Platyhelminthes, but also in some representatives of other animal lineages (e.g. annelids). The putative position of Platyhelminthes as one of the earliest branches of Bilateria led Reisinger to propose that the condensation of a nerve-net like nervous system, as found in Cnidaria, into an orthogonal CNS, as found in Platyhelminthes, could explain the subsequent evolution of the different neuronatomies of bilaterian animals (Fig. 1A) (Hanström, 1928; Reisinger, 1925; Reisinger, 1971; Steinböck, 1966). In this way, the loss of the dorsal longitudinal cords of the ancestral orthogon would have originated the ventral cords found in many protostomian lineages, while the loss of the ventral cords of the orthogon would explain the dorsal location of the nerve cord in chordates (Fig. 1A). However, current molecular phylogenies do not place

Platyhelminthes as the sister group of Bilateria (Dunn et al., 2008; Kocot et al., 2016; Laumer et al., 2015; Struck et al., 2014), but well-nested within Spiralia (see “The nervous system in the animal phylogeny" section below; Fig. 2), a major bilaterian clade that comprises animal groups with diverse neuroanatomies. Apart from Platyhelminthes, only a few other lineages, such as some annelids and mollusks (solenogastres, polyplacophorans and monoplacophorans) (Bullock and Horridge, 1965; 
110 Schmidt-Rhaesa, 2007; Schmidt-Rhaesa et al., 2016), exhibit a more or less evident

111 orthogonal-like CNS (Fig. 2). It is thus unlikely that the platyhelminth orthogonal CNS

112 arrangement represents the ancestral neuroanatomy of Spiralia, because if it does, it was

113 then lost or heavily modified in most other spiralian taxa. Moreover, clear orthogonal

114 CNS are absent or at least unclear in other bilaterian taxa (Bullock and Horridge, 1965;

115 Schmidt-Rhaesa, 2007; Schmidt-Rhaesa et al., 2016), and the ancestral condition for

116 Xenacoelomorpha, the sister taxa to all remaining bilaterians (see "The nervous system

117 in the animal phylogeny" section below) is most likely a diffuse nerve net without any

118 neural condensations (Hejnol and Pang, 2016). Therefore, the presence of an orthogonal

119 arrangement of the neural condensations in the last common bilaterian ancestor is not

120 supported.

121

The 'oral nerve ring' scenario

123 Based on their observations of onychophoran development, Balfour (1883) and

124 Sedgwick (1884) proposed the idea that the oral nerve ring of anthozoan cnidarians (e.g.

125 sea anemones) directly corresponds to the longitudinal nerve cords of bilaterian animals

126 (Fig. 1B). In onychophorans (i.e. velvet worms), the ventral longitudinal cords develop

127 from the lateral ectoderm of the transient embryonic opening called mouth-anus furrow

128 (Sedgwick, 1884-1885), which the authors assumed to be the blastopore and equivalent

129 to the anthozoan mouth, which is also surrounded by a nerve ring (Schmidt-Rhaesa et

130 al., 2016). By stretching the anthozoan mouth along the cnidarian directive axis, the oral

131 nerve ring would turn into the ventrally located, paired longitudinal cords of many

132 protostomian (Fig. 1B), process recapitulated during onychophoran development

133 (Balfour, 1883; Sedgwick, 1884). This scenario was also extended to explain the

134 evolution of other bilaterian organs systems, such as coeloms, an alimentary canal, and 
135 axial relationships (see as an example the 'Enterocoely' scenario and the amphistomy

136 concept; (Arendt et al., 2016; Remane, 1952)). However, recent investigations of

137 onychophoran development show that the opening that Balfour and Sedgwick

138 interpreted as a blastopore is instead an onychophoran-specific transient embryonic

139 structure, likely related to the high yolk content of these embryos (Janssen and Budd,

140 2017; Janssen et al., 2015). Furthermore, neural architectures that are different from a

141 ventral centralized nerve cord (e.g. dorsal cords) cannot be explained when the neural

142 tissue arises only from the blastoporal rim (Fig. 1B) and recent comparative

143 developmental studies demonstrate that the blastoporal behavior does not recapitulate

144 ancestral evolutionary events, but are the result of the specific molecular and cell fate

145 patterning of each embryo (Martín-Durán et al., 2016). From a phylogenetic

146 perspective, a diffuse nerve net is the most probable neuroanatomical character in the

147 last common cnidarian-bilaterian ancestor (Hejnol and Rentzsch, 2015; Schmidt-

148 Rhaesa, 2007), thus rendering the oral condensation of anthozoan cnidarians as a neural

149 specialization unrelated to the longitudinal nerve cords of bilaterians.

150

151 The 'nemertean' and 'annelid' scenarios

152 The 'nemertean' scenario (Hubrecht, 1883, 1887; Jensen, 1963) proposes

153 nemerteans as the starting point for the evolution of dorsal and ventral nerve cords in

154 other bilaterian lineages. Because nemerteans have lateral nerve cords (Fig. 2),

155 Hubrecht speculated that their movement to the dorsal side could lead to the dorsal

156 nerve cord of chordates, and the opposite movement would have originated the ventrally

157 centralized longitudinal cords of Protostomia (Fig. 1C). Similarly, Anton Dohrn (Dohrn,

158 1875) proposed a polychaete annelid as the closest relative of the chordates, explaining

159 the evolution of the dorsal nerve cord of chordates by an inversion of the dorsoventral 
160 axis of the ancestral adult polychaete (Fig. 1D). However, no extant animal directly

161 resembles an ancient form, meaning that the last common ancestor of a clade does not

162 need to be similar to the species at the tips. Today, nemerteans and annelids are well

163 nested within Trochozoa, together with mollusks, brachiopods and phoronids, among

164 other lineages (Kocot et al., 2016; Laumer et al., 2015; Struck et al., 2014). The

165 diversity of neural architectures found in Trochozoa, and Spiralia generally (Fig. 2),

166 suggests that a relatively simple nervous system with ventral paired nerve cords, as

167 observed in meiofaunal taxa like gnatiferans, gastrotrichs and flatworms, is probably

168 ancestral for this group (Hejnol and Lowe, 2015; Struck et al., 2014), thus making very

169 unlikely the evolutionary scenarios proposed by Hubrecht and Dohrn, which implied

170 more elaborated CNS as ancestral conditions.

171

172 The nervous system in the animal phylogeny

173 As described above, most scenarios for the evolution of the nervous system were

174 strongly influenced by pre-cladistic considerations of animal interrelationships.

175 However, our view of the animal tree of life has changed profoundly in the last two

176 decades, since the advent of molecular phylogenies (Dunn et al., 2014). Bilaterian

177 lineages -those with anteroposterior, dorsoventral, and left-right axes- have been

178 rearranged into three major monophyletic groups, Deuterostomia, Ecdysozoa, and

179 Spiralia (Fig. 2), with Deuterostomia (e.g. vertebrates) being the sister taxa to

180 Ecdysozoa (e.g. arthropods) and Spiralia (e.g. annelids) (Aguinaldo et al., 1997; Laumer

181 et al., 2015). Although the internal phylogeny of these three major clades still shows

182 some uncertainties (Dunn et al., 2014; Giribet, 2016), there is robust evidence placing

183 Xenacoelomorpha (e.g. acoel worms), which was previously placed within

184 Platyhelminthes, as the sister group to all remaining bilaterians (Cannon et al., 2016; 
185 Ruiz-Trillo et al., 1999). The former Coelenterata (Cnidaria+Ctenophora) has little

186

187

188

189

190

191

193

194

195

196

197

198

199

200

201

202

203

204

205

206

207

208

209 support (Ryan et al., 2013; Simion et al., 2017; Whelan et al., 2015), and Cnidaria now stands alone as the sister group to Bilateria. The position of Ctenophora is still controversial (Shen et al., 2017; Simion et al., 2017), but most recent analyses place this group as the sister lineage to all remaining animals.

The new animal phylogeny generates uncertainty around central questions on nervous system evolution that were previously thought settled (Hejnol and Lowe, 2015; Liebeskind et al., 2016; Ryan, 2014). Ctenophores have neurons and a diffuse nerve net, which are absent in sponges and placozoans (Bullock and Horridge, 1965) (Fig. 2). Therefore, the animal nervous system either has a single origin and got independently lost in Porifera and Placozoa or evolved twice in Ctenophora and Cnidaria+Bilateria (Jekely et al., 2015; Liebeskind et al., 2016; Moroz et al., 2014; Ryan, 2014; Ryan et al., 2013; Simion et al., 2017) (Fig. 3). Unfortunately, developmental studies on ctenophore neurogenesis that could shed light on this debate are very limited (Martindale and Henry, 1999; Norekian and Moroz, 2016). Gene expression studies in the ctenophore Mnemiopsis leidyi could so far not provide evidence for the homology of the developmental pathways involved in neurogenesis in ctenophores (Pang and Martindale, 2008; Schnitzler et al., 2014; Simmons et al., 2012). However, the absence of core bilaterian neurogenic regulators in ctenophore gene repertoires (Moroz et al., 2014; Ryan et al., 2013) and the failed attempt to identify neural cell types by using typical pan-neural orthologs (Sebé-Pedrós et al., 2018) suggest that if homologous, the gene networks controlling the specification and development of neurons might be significantly different between these animals and cnidarians and bilaterians. Similarly, the internal rearrangement of Bilateria has moved taxa that were once key to explain 
210 nervous system diversification (e.g. platyhelminths, annelids, onychophorans,

211 nemerteans; see above) to internal nodes within the Ecdysozoa and Spiralia (Dunn et al.,

212 2014) (Fig. 2). This, together with the vast diversity of CNS anatomies within Bilateria

213 (Schmidt-Rhaesa et al., 2016), has blurred the identification of the ancestral bilaterian

214 neuroanatomy (Fig. 2), and in particular of the sequence of events that led to the

215 emergence of the vertebrate CNS, with an anterior brain and a medially condensed

216 dorsal nerve cord.

As some traditional ideas have proven wrong, the generally robust new

219 phylogenetic framework has set the foundations for a reinterpretation of animal

220 evolution (Dunn et al., 2014; Giribet, 2016). For instance, the placement of

221 xenacoelomorphs, which ancestrally solely possessed a diffuse basiepidermal nerve net

222 (Achatz et al., 2013; Hejnol and Pang, 2016; Raikova et al., 2016), as the intermediate

223 taxon between cnidarians and the remaining bilaterians decouples the evolution of a

224 CNS from the emergence of Bilateria and suggests that neural condensations have

225 evolved repeatedly within bilaterian animals.

226

\section{The early development of the CNS in Bilateria}

With most traditional views on nervous system evolution falsified, a thorough

229 comparative investigation of neurogenesis under an unbiased phylogenetic framework

230 emerges as the alternative to reconstruct ancestral character states in the evolution of the

231 nervous system. Are there comparable, and perhaps homologous processes in bilaterian

232 neurogenesis that can illuminate the origin of a CNS? In most animal embryos, the

233 primary committed cells that will hierarchically give rise to all differentiated cell types

234 of an organism are spatially organized in relation to the animal-vegetal axis of the 
235 oocyte, which is defined by the site of extrusion of the polar bodies (i.e. animal pole)

236 (Goldstein and Freeman, 1997; Martindale and Hejnol, 2009; von Baer, 1834). The

237 earliest events of cell fate specification occur during cleavage, so that precursor cells

238 immigrate and acquire their final embryonic destinations during gastrulation. Therefore,

239 it is possible to identify the prospective embryonic areas, or even cells, that will

240 eventually contribute to the formation of the nervous system at these very early

241 embryonic stages. This can be inferred from the expression of upstream neurogenic

242 genes (see below), but ideally cell fates should be demonstrated by actual cell tracking

243 techniques (Amat and Keller, 2013; Hejnol and Schnabel, 2006; Sulston et al., 1983).

244 Although limited to a handful of animal lineages, fate mapping gives a cellular

245 ontogenetic context to molecular data, thus improving evolutionary comparisons, and

246 can offer a general framework to understand common principles in nervous system

247 development in animals.

248

249

In ctenophores, neuronal and ectodermal cell fates have a common

250 developmental origin (Martindale and Henry, 1999), yet the specification and

251 development of neurons appear to be a rather late process in development (Moroz et al.,

252 2014; Norekian and Moroz, 2016). Differently from ctenophores, the cnidarian nerve

253 net develops from both the ectoderm and the endoderm in a process that starts early in

254 development, before the onset of gastrulation (Nakanishi et al., 2012; Richards and

255 Rentzsch, 2014) (Fig. 4). Intracellular injections of fluorescent dyes in early

256 blastomeres of the acoel Neochildia fusca demonstrate that the diffuse basiepidermal

257 nerve net shares a common developmental origin only with the ectoderm (Henry et al.,

258 2000) (Fig. 4). The sensory statocyst, however, appears to derive from, or at least

259 require the presence of, the vegetal macromeres (endomesoderm) for its differentiation 
260 (Boyer, 1971). Indeed, the nervous system has a predominant ectodermal origin in all 261 Bilateria.

In Spiralia, cell lineage studies have greatly concentrated in those animal groups

264 that share the stereotypical quartet-spiral cleavage program (Hejnol, 2010; Henry and

265 Martindale, 1999). This is a broadly conserved early embryonic program, probably

266 ancestral to the whole Spiralia (Hejnol, 2010; Henry, 2014), where embryos get divided

267 in four quadrants, named A to D, each roughly forming the left, anteroventral, right, and

268 posterodorsal region of the animal respectively. The cell division from the 4 - to the 8-

269 cell stage is asymmetric, with the four blastomeres at the vegetal pole being larger (i.e.

270 macromeres) than the cells at the animal top (i.e. micromeres). Before gastrulation,

271 macromeres bud off four tiers of micromeres, which are named 1 to 4 (to represent the

272 tier) and a to $\mathrm{d}$ (to represent the quadrant they come from) in the classic nomenclature

273 used to describe spiralian cell lineages (Conklin, 1897). Generally, in groups such as

274 polyclad flatworms, mollusks, annelids and nemerteans, the brain and anterior sensory

275 organs (e.g. the larval apical tuft and photoreceptors) originate from the first tier, or

276 quartet, of animal micromeres, which also form the head ectoderm (Henry and

277 Martindale, 1999) (Fig. 4). Other components of the nervous system, such as the nerve

278 cords, originate from derivatives of the second and third quartet micromeres (Henry and

279 Martindale, 1999). For instance, derivatives of the first quartet micromers $\left(1 \mathrm{a}^{1}-1 \mathrm{~d}^{1}\right)$

280 form the brain in the annelid Capitella teleta, while the blastomere $2 \mathrm{~d}$ gives rise to

281 dorsal parts of the brain and the ventral nerve cord, and the 3 a cell forms isolated

282 neurons (Meyer et al., 2010; Meyer and Seaver, 2010). However, the first quartet

283 micromers also contribute to anterior regions of the ventral nerve cord in the annelid $P$.

284 dumerilii (Ackermann et al., 2005), and in the mollusk gastropod Crepidula fornicata 
285 the visceral nerve cords arise from the 2b blastomeres (Hejnol et al., 2007; Lyons et al., 286 2015). In the nemertean Cerebratulus lacteus, the larval nervous system originates from

287 1c, 1d, 2a, 2c, 2d, 3c and 3d (Henry and Martindale, 1998), and in the cyphonautes larva 288 of the bryozoan Membranipora membranacea, which has modified the spiral cleavage, 289 the apical organ forms from the 1a-1d blastomeres (Vellutini et al., 2017). Therefore, 290 there is a significant degree of interspecies variation underlying general spiralian 291 developmental plans. This, together with the lack of detailed cell lineage investigations 292 in gnathiferans (rotifers, gnathostomulids, and micrognathozoans) and gastrotrichs 293 makes difficult to confidently infer the exact cellular mode of nervous system 294 development for Spiralia.

297 Scalidophora, Nematoida, and Panarthropoda (Dunn et al., 2014). There is virtually no 298 cellular data on the embryonic development of the nervous system in Scalidophora (i.e. 299 priapulid worms, kynorynchs and loriciferans), where only the expression of the 300 nervous system marker otx in the priapulid Priapulus caudatus indirectly suggests that 301 the circumoral brain originates from ectodermal cells at the introvert-trunk boundary 302 (Martin-Duran et al., 2012). This evident lack of knowledge stands in stark contrast 303 with the high-resolution cell lineage of the nervous system in Nematoda, in particular in 304 the developmental research system Caenorhabditis elegans. In this nematode, the 305 nervous system is mostly formed from the ectodermal founder cell AB, with some 306 contribution of the C blastomere, and even the mesodermal precursor MS (Sulston et 307 al., 1983) (Fig. 4). During gastrulation, AB precursors spread from anterior to posterior, 308 and trunk ventral neuroblasts finish the closure of the blastopore as they get internalized 309 by dorsally expanding epithelial cells (Sulston et al., 1983). Unfortunately, less is 
310 known for most other nematode lineages, as well as for Nematomorpha, the sister group

311 of nematodes. Within Panarthropoda, cell lineage data in the tardigrade Thulinia

312 stephaniae demonstrates that the brain and the ventral nerve ganglia develop from

313 separate neural precursors that delaminate from the ectoderm (Hejnol and Schnabel,

314 2005). Direct cell tracking is missing in onychophorans, but morphological and gene

315 expression data indicate that delamination of neural progenitors from the neuroectoderm

316 forms the nervous system (Mayer and Whitington, 2009). A similar, more organized

317 and invariant process is seen in crustaceans and insects (Fig. 4), where isolated

318 neuroblasts that either delaminate (insects) or remain epithelial (crustaceans) divide

319 asymmetrically to form the neurons (Dohle et al., 2004; Whitington, 1996). In addition,

320 some parts of the nervous system (optic lobes, stomatogastric nervous system,

321 neuroendocrine system) involve the ingression of larger groups of neuroectodermal

322 precursors, a process that seems to be more prevalent in arthropod groups like

323 chelicerates and myriapods (Stollewerk and Chipman, 2006). As in Spiralia, the lack of

324 detailed studies in scalidophorans and nematodes with less derived nervous system

325 development hampers inferring the ancestral mode of nervous system development in

326 Ecdysozoa, and thus in Protostomia as a whole.

In Deuterostomia, direct tracing of the fate of individual blastomeres into

329 neurons has not been performed in hemichordates. However, the basiepidermal nerve

330 net probably derives from the animal mesomeres and macromeres in Saccoglossus

331 kowalevskii, which also form the ectoderm of the embryo (Colwin and Colwin, 1951)

332 (Fig. 4). In line with their diffuse basiepidermal nerve net, early neurogenic markers

333 like $\operatorname{sox} B$ and elav are ubiquitously expressed in the ectoderm of the gastrula of $S$.

334 kowalevskii (Cunningham and Casey, 2014; Lowe et al., 2003). A similar fate map is 
335 observed in sea urchins (Cameron et al., 1987) (Fig. 4), but the canonical Wnt pathway

336 and the Nodal and BMP2/4 pathway restricts neurogenesis to the anterior and the ciliary

337 band neuroectoderm (Angerer et al., 2011). However, sea urchin larvae also form a

338 subset of their neurons from pharyngeal endodermal derivatives (Wei et al., 2011).

339 Chordates, on the other hand, exhibit a highly centralized nervous system, which

340 develops from the dorsal neural plate, of ectodermal origin (Lumsden and Krumlauf,

341 1996) (Fig. 4). In cephalochordates and vertebrates there is no invariant blastomere

342 lineage for the neural plate, but a defined set of blastomeres generates the neural plate in

343 ascidians, in accordance with their invariant cell lineage (Nicol and Meinertzhagen,

344 1988; Nishida, 1987). Therefore, the situation observed in hemichordates is reminiscent

345 of that of cnidarians and xenacoelomorphs, and might thus represent the ancestral

346 condition for Deuterostomia (Holland, 2003; Lowe et al., 2015), albeit this

347 interpretation is still debated (Arendt et al., 2016; Holland et al., 2013).

This brief outline of early bilaterian neurogenesis already highlights how diverse

350 the formation of the nervous system is in animal embryos. The uncertainties about the

351 homology between the ctenophore nervous system and the cnidarian/bilaterian neural

352 tissues (Fig. 3) limit drawing far-reaching conclusions regarding the ancestral metazoan

353 mode of neural development. However, the comparison between Cnidaria and Bilateria

354 strongly suggests that the neurogenic potential became restricted to the ectoderm at the

355 onset of Bilateria, and thus the rare cases of mixed germ-layer origins, like in

356 nematodes (Sulston et al., 1983) and echinoderms (Wei et al., 2011), are probably

357 secondary deployments of neurogenic programs in cellular lineages that give rise to

358 mostly mesodermal (as in nematodes) and endodermal (as in echinoderms) derivatives.

359 How the development of the nervous system became restricted to the ectoderm in 
360 Bilateria is still unclear (Martindale and Hejnol, 2009), and will require of detailed

361 mechanistic investigations in key lineages of the animal phylogeny, such as cnidarians,

362 xenacoelomorphs, hemichordates, scalidophorans and gnatiferans. In this regard,

363 neurogenesis is largely unknown in many bilaterian taxa, which as we have already

364 pointed out hampers the reconstruction of homologous developmental processes for the

365 major bilaterian clades. Despite this paucity of knowledge, our current understanding of

366 cnidarian and bilaterian neurogenesis has allowed refuting most traditional scenarios for

367 CNS evolution (see above) and has set the grounds for a more accurate interpretation of

368 an increasing amount of molecular data in a growing number of bilaterian taxa.

The molecular patterning of the bilaterian nervous system

The variation in the embryonic fate maps and cellular aspects of nervous system

372 development summarized above ultimately relies on modifications of the underlying

373 neurogenic processes. In this respect, the comparison of expression patterns of

374 orthologous genes involved in the specification and regionalization of bilaterian neural

375 tissues has transformed the study of CNS development and evolution (Arendt et al.,

376 2016; Hejnol and Lowe, 2015; Holland, 2015; Holland et al., 2013; Puelles and Ferran,

377 2012; Strausfeld and Hirth, 2013; Tosches and Arendt, 2013). Although in many cases

378 there is a lack of functional investigations of the genes used for comparisons, gene

379 expression data has been widely used to propose evolutionary scenarios and working

380 hypotheses (Arendt et al., 2016; Hejnol and Lowe, 2015; Holland et al., 2013; Lowe et

381 al., 2006; Lowe et al., 2003). For instance, the similar molecular profiles of the

382 arthropod mushroom bodies with anterior neural condensations in vertebrates, the

383 annelid Platynereis dumerilii, and other invertebrate taxa has grounded the hypothesis

384 that complex brain centers were already present in the last common bilaterian ancestor 
385 (Tomer et al., 2010; Wolff and Strausfeld, 2015). As sequencing techniques and

386 molecular methods improved, this comparative molecular approach incorporated a

387 growing number of bilaterian lineages to CNS evolutionary discussions, thus

388 encompassing a significant proportion of the diversity of neural anatomies and

389 developmental modes found in Bilateria. As a result, many of the evolutionary

390 interpretations originally based on data from a few bilaterian lineages have been either

391 solidified or questioned (Hejnol and Lowe, 2015). In the following two sections, we

392 review how increased taxon sampling has affected the use of anteroposterior and

393 dorsoventral neuronal patterning to explain the evolution of the brain and nerve cords

394 respectively.

395

396

\section{1) Anteroposterior patterning}

As many other morphological features, the nervous system of most bilaterian

animals is regionalized along the anteroposterior axis (Bullock and Horridge, 1965).

This regionalization occurs at both the morphological and the functional level and gets

400 reflected on how upstream neural regulatory genes and downstream terminal

401 differentiation genes are deployed along the anteroposterior axis of the neural tissue. A

402 large number of transcription factors (e.g. six3/6, foxQ2, otx, otp, fezf, pax6, pax 2/5/8,

403 en, irx genes, Hox genes) and signaling pathways (e.g. the Wnt/bcatening pathway,

404 Hedgehog pathway, FGF pathway, EGFR pathway) are differentially expressed along

405 the anteroposterior axis of the developing nervous system (Arendt et al., 2008; Holland

406 et al., 2013; Vermeren and Keynes, 2001). Importantly, the expression of these genes

407 often relates to anteroposterior neuroanatomical subdivisions, and as such, gene

408 expression data has been widely used to homologize nervous system compartments

409 across bilaterian lineages (Albuixech-Crespo et al., 2017; Arendt et al., 2008; Arendt 
and Nübler-Jung, 1999; Arendt et al., 2016; Hirth et al., 2003; Hunnekuhl and Akam,

411 2014; Lowe et al., 2003; Marlow et al., 2014; Pani et al., 2012; Range, 2014; Sinigaglia

412 et al., 2013; Steinmetz et al., 2011; Tessmar-Raible et al., 2007; Tomer et al., 2010;

413 Tosches and Arendt, 2013).

One of the most relevant, and still debated examples of this comparative

approach affects the anteroposterior patterning of the vertebrate CNS and the evolution

417 of a complex brain. Early in vertebrate embryogenesis, the vertebrate neural plate

becomes molecularly patterned into the basic units that will form the CNS, namely the

419 forebrain, midbrain, hindbrain, and spinal cord (Puelles, 2013; Vermeren and Keynes,

420 2001). As development proceeds, secondary organizers such as zona limitans

421 intrathalamica (ZLI) and the isthmic organizer (IsO) subdivide and specialized these

422 primary neural regions. These areas, subregions, and organizers exhibit a combination

423 of developmental genes robustly conserved among vertebrate lineages (Fig. 5),

424 supporting the homology of the vertebrate CNS neuroanatomy (Puelles and Ferran,

425 2012). Consequently, the analysis of these molecular signatures in non-vertebrate

426 chordates (i.e. tunicates and amphioxus) and hemichordates, the closest chordate

427 outgroup, have been used to trace the evolutionary origins of the vertebrate CNS

428 (Albuixech-Crespo et al., 2017; Pani et al., 2012). The analysis of an extensive gene

429 dataset in the 7-somite mid neurula embryo of the European species Branchiostoma

430 lanceolatum has shown that the amphioxus neural plate is already anteroposteriorly

431 patterned, and that these primary areas have a direct topological correspondence with

432 vertebrate CNS compartments (Albuixech-Crespo et al., 2017). However, amphioxus

433 lacks the secondary organizers ZLI and IsO (Shimeld and Holland, 2005), whose

434 emergence in the stem lineage of vertebrates could explain how a primary amphioxus- 
435 like neural plate pattern evolved into the more elaborated vertebrate CNS. Strikingly,

436 expression and functional data of ZLI and IsO markers in the hemichordate

437 Saccoglossus kowalevskii, together with the conservation of genomic Cis-regulatory

438 regions between hemichordates and vertebrates, has given compelling evidence that

439 these signaling centers predated chordates and the evolution of their complex brain

440 (Pani et al., 2012; Yao et al., 2016). In S. kowalevskii, however, the ZLI and IsO are

441 involved in the anteroposterior ectodermal pattern and the subdivision of the primary

442 body axis in proboscis, collar, and trunk (Pani et al., 2012). These findings thus propose

443 that the vertebrate CNS is a much recent innovation, evolved from the cooption of

444 preexisting ectodermal patterning gene regulatory modules that apparently got lost in

445 pre-vertebrate chordate lineages (Lowe et al., 2015; Pani et al., 2012) (Fig. 5).

Long-distance evolutionary comparisons of gene expression data have also been

448 used to homologize animal brains generally (Arendt et al., 2008; Arendt et al., 2016;

449 Hirth et al., 2003; Holland, 2015; Holland et al., 2013; Strausfeld and Hirth, 2013;

450 Tosches and Arendt, 2013). Indeed, the anteroposterior neural domains of transcription

451 factors such as otx, pax 2/5/8, and Hox genes have been used to homologize the tripartite

452 organization of the arthropod brain (protocerebrum, deuterocerebrum and

453 tritocerebrum) with the forebrain, midbrain, and hindbrain of vertebrates (Hirth et al.,

454 2003). Similarly, comparable antibody immunoreactivity and gene expression data

455 suggested the shared ancestry of complex sensory-associated brain centers, as those

456 observed in arthropods, vertebrates, annelids, platyhelminths, and nemerteans (Tomer et

457 al., 2010; Wolff and Strausfeld, 2015). Generally, these hypotheses suffer from low, and

458 sometimes biased, taxonomic sampling, and thus it still remains to be seen how the

459 inclusion of bilaterian lineages that lack elaborated brain centers affects them. For 
460 instance, immunoreactivity against pCaMKII, a protein enriched in arthropod

461 mushroom bodies, is broadly detected in the larval nervous system of priapulid worms,

462 whose nervous system comprises a simple circumoral nerve ring and a single caudal

463 bipolar neuron as ventral nerve cord (Martin-Duran et al., 2016). A similar case is seen

464 in the free-swimming larvae of the brachiopods Terebratalia transversa and

465 Novocrania anomala (Fig. 5), which have only poorly developed anterior

466 condensations, associated to an apical tuft in T. transversa (Santagata, 2011). In these

467 larvae, genes associated to brain signaling centers like the ZLI and IsO and neural

468 regional patterning like Hox genes are also expressed staggered along the

469 anteroposterior axis (Martín-Durán et al., 2016; Santagata et al., 2012; Schiemann et al.,

470 2017; Vellutini and Hejnol, 2016), but demarcating ectodermal domains rather than

471 different areas of the CNS. Furthermore, the expression of anteroposterior patterning

472 genes such as six $3 / 6$, otx, fox $Q 2$, and gsc in bilaterian and cnidarian larvae suggest that

473 brain-related genes are also generally involved in (neuro)ectodermal patterning (Hejnol

474 and Martindale, 2008; Hiebert and Maslakova, 2015; Marlow et al., 2014; Martín-Durán

475 et al., 2015; Nederbragt et al., 2002; Sinigaglia et al., 2013; Steinmetz et al., 2011;

476 Wollesen et al., 2015). Therefore, scenarios that favor a complex brain as an ancestral

477 feature of Bilateria (Arendt et al., 2008; Arendt et al., 2016; Hirth et al., 2003; Holland,

478 2015; Holland et al., 2013; Strausfeld and Hirth, 2013; Tosches and Arendt, 2013), and

479 thus extensive simplification in most bilaterian lineages, are confronted with data

480 arguing for a convergent, stepwise evolution of bilaterian complex CNS architectures

481 (Pani et al., 2012).

482

483 2) Dorsoventral patterning 
485 presence of a medially unpaired condensed nerve cord (Bullock and Horridge, 1965;

486 Schmidt-Rhaesa, 2007) (Fig. 2). Whereas the nerve cord is located ventrally in

487 arthropods, it is dorsally positioned in chordates, which led the French naturalist

488 Geoffroy Saint-Hilaire to propose the homology between the arthropod ventral side and 489 the chordate dorsal side already on 1822 (Geoffroy Saint-Hilaire, 1822). Almost two

490 centuries later, the finding that similar genes and signaling pathways (e.g. BMP

491 pathway) were expressed in the embryonic territories giving rise to the nerve cords in

492 the fruitfly D. melanogaster and vertebrates revived those classic ideas, and in

493 particular those involving a dorsoventral inversion of the CNS in the stem lineage of

494 Chordata (Arendt and Nübler-Jung, 1994; De Robertis and Sasai, 1996). In this context, 495 orthologous members of the $N K 2.1, N K 2.2, N K 6$, pax6, pax3/7, and $m s x$ gene families 496 are deployed in a similar fashion along the dorsoventral axis of the nerve cord in 497 insects, vertebrates and the polychaete annelid P. dumerilii (Denes et al., 2007) (Fig. 6).

498 In insects and vertebrates, the expression of these genes is required for the proper

499 patterning of the nerve cord (Cornell and Ohlen, 2000), and their expression is

500 associated with the location of distinct neuronal populations in these three bilaterian

501 lineages (Arendt et al., 2008). Although the upstream regulators and downstream

502 effectors of dorsoventral patterning genes differ between Drosophila and vertebrates

503 (Cornell and Ohlen, 2000; Winterbottom et al., 2010), the striking similarities observed

504 in the dorsoventral patterning of the nerve cord between insects, vertebrates, and the

505 annelid $P$. dumerilii solidified the idea that a CNS with a medially condensed ventral 506 nerve cord is ancestral for Bilateria (Arendt et al., 2008; Arendt et al., 2016; Denes et

507 al., 2007; Holland et al., 2013; Tosches and Arendt, 2013). 
510 scenario (Kaul-Strehlow et al., 2017; Lowe et al., 2006; Lowe et al., 2003; Okkema et

511 al., 1997) (Fig. 6). The neural anatomy of these two lineages differs considerably from

512 that of vertebrates, insects, and annelids. Hemichordates have a diffuse nerve net

513 throughout the body, with one dorsal and one ventral nerve cord running along their

514 trunks (Bullock and Horridge, 1965). Nematodes, on the other hand, have a main

515 ventral and dorsal nerve cord, and additional pairs of lateral neurite bundles (Bullock

516 and Horridge, 1965). In the hemichordates S. kowalevskii and Balanoglossus

517 misakiensis, the genes $N K 2.1, N K 2.2$, pax6 and $m s x$ do not exhibit a staggered

518 dorsoventral arrangement, but their expression is either confined to endoderm (e.g.

$519 N K 2.2)$ or to particular ectodermal areas along the anteroposterior axis (e.g. NK2.1,

520 pax6, and msx) (Kaul-Strehlow et al., 2017; Lowe et al., 2006; Lowe et al., 2003).

521 Similarly, only pax6 and $m s x$ are expressed in connection to the nervous system in the

522 nematode C. elegans, (Chisholm and Horvitz, 1995; Du and Chalfie, 2001). Therefore,

523 it is unclear whether the different expression of dorsoventral patterning genes in

524 hemichordates and nematodes are derived situations, perhaps related to their different

525 neuroanatomies and life styles (Arendt, 2018; Denes et al., 2007), or suggest that the

526 similarities between lineages with a single medial nerve cord evolved convergently

527 (Lowe et al., 2006; Martin-Duran et al., 2018).

A recent study on the expression of dorsoventral nerve cord patterning genes in

530 xenacoelomorph worms and representatives of four major spiralian lineages has shed

531 new light into this debate (Martin-Duran et al., 2018). Character state reconstructions

532 suggest that a diffuse nerve net and one pair of ventral nerve chords are the most likely

533 ancestral neuroanatomies of Xenacoelomorpha and Spiralia respectively (Hejnol and 
534 Lowe, 2015; Hejnol and Pang, 2016). However, trunk neuroarchitecture vary widely

535 within these two bilaterian lineages, with acoelomorph species showing independently

536 evolved neural condensations and spiralian lineages like annelids exhibiting medially

537 condensed unpaired nerve cords (Bullock and Horridge, 1965; Hejnol and Lowe, 2015;

538 Schmidt-Rhaesa, 2007) (Fig. 2). In line with this morphological diversity, the

539 expression of dorsoventral nerve cord patterning genes varies significantly among

540 xenacoelomorpha and spiralian lineages (Buresi et al., 2016; Forsthoefel et al., 2012;

541 Franke et al., 2015; Janssen, 2017; Mannini et al., 2008; Martin-Duran et al., 2018;

542 Martín-Durán et al., 2016; Vellutini et al., 2017), even between closely related species

543 like the annelids Owenia fusiformis and Platynereis dumerilii that share the presence of

544 a medially condensed unpaired nerve cord (Denes et al., 2007; Martin-Duran et al.,

545 2018) (Fig. 6). Remarkably, a similar case is found in Chordata, where non-vertebrate

546 chordates, such as amphioxus and tunicates, differ from vertebrates in the arrangement

547 of dorsoventral nerve cord patterning genes, yet all of them share the presence of a

548 dorsal neural tube (Holland et al., 1998; Ristoratore et al., 1999; Stolfi and Levine,

549 2011) (Fig. 6). It appears thus clear that dorsoventral nerve cord patterning and trunk

550 neuroanatomy has evolved independently in several animal lineages, and that the

551 diversity of expression arrangements of dorsoventral patterning genes is more the norm

552 than the exception in Bilateria, supporting the evolutionary scenario that poses the

553 similarities in dorsoventral patterning between vertebrates, Drosophila and some

554 annelids as a case of convergence (Lowe et al., 2006; Martin-Duran et al., 2018).

555 However, a more thorough investigation of the relationship between the dorsoventral

556 patterning genes and nerve cord architecture is needed, in particular regarding the actual

557 function of these transcription factors in the development of the nerve cords in most of

558 the bilaterian lineages studied to date. 


\section{Conclusions}

561 The advances in reconstructing animal relationships combined with a

562 mechanistic understanding of nervous system development in a handful of animal taxa

563 has proven essential to falsify traditional scenarios for nervous system evolution. This

564 progress has also demonstrated that the evolutionary history of the nervous system is

565 more tortuous than previously thought, with the probable convergent evolution of

566 neurons, condensed brain centers, and longitudinal nerve cords. However, freeing our

567 interpretation of nervous system evolution from preconceived recapitulative scenarios

568 has also allowed to state clear questions and research lines that will eventually help to

569 clarify evolutionary events at specific nodes of the animal phylogeny. How similar are

570 the neurons of ctenophores to those of cnidarians and bilaterians? How did the

571 neurogenic potential become mostly restricted to the ectoderm in bilaterians? Is this

572 event related to the cooption of ancestral ectodermal patterning mechanisms to the

573 development of centralized neural structures? How do conserved molecular patternings

574 generate divergent neural architectures? Are there similar developmental principles

575 between the multiple cases of nervous system condensation that can inform us of

576 common evolutionary trajectories in the diversification of animal morphology? These

577 and many other questions will ultimately require embracing animal diversity and strive

578 for acquiring a functional understanding of the developmental implications of the

579 observed molecular neural patternings. On the long run, they will pay us off with a more

580 insightful view on one of the greatest questions in science.

581

582 Acknowledgements 
583 We thank former and current lab members for support and discussion, as well as the

584 Guest Editors Clifford Ragsdale and Elizabeth Grove for the invitation to contribute

585 with this review. This work is supported by the Sars Centre core budget to AH and

586 Queen Mary University of London start-up funds to JMMD.

587

\section{$588 \quad$ References}

589 Achatz, J.G., Chiodin, M., Salvenmoser, W., Tyler, S., Martinez, P., 2013. The Acoela:

590 on their kind and kinships, especially with nemertodermatids and xenoturbellids

591 (Bilateria incertae sedis). Organisms, Diversity and Evolution 13, 267-286.

592 Ackermann, C., Dorresteijn, A., Fischer, A., 2005. Clonal domains in postlarval

593 Platynereis dumerilii (Annelida: Polychaeta). J Morphol 266, 258-280.

594 Aguinaldo, A.M., Turbeville, J.M., Linford, L.S., Rivera, M.C., Garey, J.R., Raff, R.A., 595 Lake, J.A., 1997. Evidence for a clade of nematodes, arthropods and other moulting 596 animals. Nature 387, 489-493.

597 Albuixech-Crespo, B., Lopez-Blanch, L., Burguera, D., Maeso, I., Sanchez-Arrones, L., 598 Moreno-Bravo, J.A., Somorjai, I., Pascual-Anaya, J., Puelles, E., Bovolenta, P., Garcia599 Fernandez, J., Puelles, L., Irimia, M., Ferran, J.L., 2017. Molecular regionalization of 600 the developing amphioxus neural tube challenges major partitions of the vertebrate 601 brain. PLoS Biol 15, e2001573.

602 Amat, F., Keller, P.J., 2013. Towards comprehensive cell lineage reconstructions in 603 complex organisms using light-sheet microscopy. Development, growth \& 604 differentiation 55, 563-578.

605 Angerer, L.M., Yaguchi, S., Angerer, R.C., Burke, R.D., 2011. The evolution of 606 nervous system patterning: insights from sea urchin development. Development 138, $607 \quad 3613-3623$. 
608 Arendt, D., 2018. Animal Evolution: Convergent Nerve Cords? Curr Biol 28, R225-

609 R227.

610 Arendt, D., Denes, A.S., Jékely, G., Tessmar-Raible, K., 2008. The evolution of

611 nervous system centralization. Philos. Trans. R. Soc. Lond. B Biol. Sci. 363, 1523-

6121528.

613 Arendt, D., Nübler-Jung, K., 1994. Inversion of dorsoventral axis? Nature 371, 26.

614 Arendt, D., Nübler-Jung, K., 1999. Comparison of early nerve cord development in 615 insects and vertebrates. Development 126, 2309-2325.

616 Arendt, D., Tosches, M.A., Marlow, H., 2016. From nerve net to nerve ring, nerve cord

617 and brain--evolution of the nervous system. Nat Rev Neurosci 17, 61-72.

618 Balfour, F.M., 1883. The Anatomy and Development of Peripatus capensis. Quart J

619 Microsc Sci 23, 213-259.

620 Boyer, B.C., 1971. Regulative development in a spiralian embryo as shown by cell

621 deletion experiments on the Acoel, Childia. The Journal of experimental zoology 176, $62297-105$.

623 Bullock, T.H., Horridge, G.A., 1965. Structure and Function in the Nervous Systems of 624 Invertebrates. W. H. Freemand and Company, San Francisco and London.

625 Buresi, A., Andouche, A., Navet, S., Bassaglia, Y., Bonnaud-Ponticelli, L., Baratte, S., 626 2016. Nervous system development in cephalopods: How egg yolk-richness modifies 627 the topology of the mediolateral patterning system. Dev Biol 415, 143-156.

628 Cameron, R.A., Hough-Evans, B.R., Britten, R.J., Davidson, E.H., 1987. Lineage and 629 fate of each blastomere of the eight-cell sea urchin embryo. Genes Dev 1, 75-85.

630 Cannon, J.T., Vellutini, B.C., Smith, J., 3rd, Ronquist, F., Jondelius, U., Hejnol, A.,

631 2016. Xenacoelomorpha is the sister group to Nephrozoa. Nature 530, 89-93. 
632 Chisholm, A.D., Horvitz, H.R., 1995. Patterning of the Caenorhabditis elegans head

633 region by the Pax-6 family member vab-3. Nature 377, 52-55.

634 Colwin, A.L., Colwin, L.H., 1951. Relationships between the egg and larva of

635 saccoglossus kowalevskii (enteropneusta): Axes and planes; general prospective

636 significance of the early blastomeres. Journal of Experimental Zoology 117, 111-137.

637 Conklin, E.G., 1897. The embryology of Crepidula. Ginn.

638 Cornell, R.A., Ohlen, T.V., 2000. Vnd/nkx, ind/gsh, and $m s h / m s x$ : conserved regulators

639 of dorsoventral neural patterning? Curr Opin Neurobiol 10, 63-71.

640 Cunningham, D., Casey, E.S., 2014. Spatiotemporal development of the embryonic

641 nervous system of Saccoglossus kowalevskii. Dev Biol 386, 252-263.

642 De Robertis, E.M., Sasai, Y., 1996. A common plan for dorsoventral patterning in

643 Bilateria. Nature 380, 37-40.

644 Denes, A.S., Jékely, G., Steinmetz, P.R.H., Raible, F., Snyman, H., Prud'homme, B.,

645 Ferrier, D.E.K., Balavoine, G., Arendt, D., 2007. Molecular architecture of annelid

646 nerve cord supports common origin of nervous system centralization in Bilateria. Cell

$647129,277-288$.

648 Dohle, W., Gerberding, M., Hejnol, A., Scholtz, G., 2004. Cell lineage, segment

649 differentiation, and gene expression in crustaceans, in: Scholtz, G. (Ed.), Evolutionary

650 Developmental Biology of Crustacea. A.A. Balkema, Lisse.

651 Dohrn, A., 1875. Der Ursprung der Wirbelthiere und das Princip des

652 Functionswechsels. Verlag von Wilhelm Engelmann, Leipzig.

653 Dougherty, E.C., 1963. The Lower Metazoa. University of California Press, Berkeley $654 \quad$ Los Angeles, p. 478.

655 Du, H., Chalfie, M., 2001. Genes regulating touch cell development in Caenorhabditis 656 elegans. Genetics 158, 197-207. 
657 Dunn, C.W., Giribet, G., Edgecombe, G.D., Hejnol, A., 2014. Animal phylogeny and its 658 evolutionary implications. Ann Rev Ecol Evol Syst 45, 371-395.

659 Dunn, C.W., Hejnol, A., Matus, D.Q., Pang, K., Browne, W.E., Smith, S.A., Seaver, E.,

660 Rouse, G.W., Obst, M., Edgecombe, G.D., Sorensen, M.V., Haddock, S.H., Schmidt-

661 Rhaesa, A., Okusu, A., Kristensen, R.M., Wheeler, W.C., Martindale, M.Q., Giribet, G., 662 2008. Broad phylogenomic sampling improves resolution of the animal tree of life.

663 Nature 452, 745-749.

664 Forsthoefel, D.J., James, N.P., Escobar, D.J., Stary, J.M., Vieira, A.P., Waters, F.A.,

665 Newmark, P.A., 2012. An RNAi screen reveals intestinal regulators of branching

666 morphogenesis, differentiation, and stem cell proliferation in planarians. Dev Cell 23,

$667 \quad 691-704$.

668 Franke, F.A., Schumann, I., Hering, L., Mayer, G., 2015. Phylogenetic analysis and 669 expression patterns of Pax genes in the onychophoran Euperipatoides rowelli reveal a 670 novel bilaterian Pax subfamily. Evol Dev 17, 3-20.

671 Geoffroy Saint-Hilaire, E., 1822. Considérations Générale sur la Vértèbres. Mém. Mus. 672 Hist. Nat. 9, 89-114.

673 Giribet, G., 2016. Genomics and the animal tree of life: conflicts and future prospects. 674 Zool Scripta 45, 14-21.

675 Goldstein, B., Freeman, G., 1997. Axis specification in animal development. Bioessays $67619,105-116$.

677 Haeckel, E., 1866. Generelle Morphologie der Organismen. Verlag von Georg Reimer, 678 Berlin.

679 Hanström, B., 1928. Vergleichende Anatomie des Nervensystems der Wirblellosen 680 Tiere. Verlag von Julius Springer, Berlin. 
681 Hejnol, A., 2010. A Twist in Time-The Evolution of Spiral Cleavage in the Light of

682 Animal Phylogeny. Integrative and comparative biology 50, 695-706.

683 Hejnol, A., Lowe, C.J., 2015. Embracing the comparative approach: how robust

684 phylogenies and broader developmental sampling impacts the understanding of nervous 685 system evolution. Philos Trans R Soc Lond B Biol Sci 370.

686 Hejnol, A., Martindale, M.Q., 2008. Acoel development indicates the independent 687 evolution of the bilaterian mouth and anus. Nature 456, 382-386.

688 Hejnol, A., Martindale, M.Q., Henry, J.Q., 2007. High-resolution fate map of the snail

689 Crepidula fornicata: the origins of ciliary bands, nervous system, and muscular 690 elements. Dev Biol 305, 63-76.

691 Hejnol, A., Obst, M., Stamatakis, A., Ott, M., Rouse, G.W., Edgecombe, G.D., 692 Martinez, P., Baguñá, J., Bailly, X., Jondelius, U., Wiens, M., Müller, W.E.G., Seaver, 693 E., Wheeler, W.C., Martindale, M.Q., Giribet, G., Dunn, C.W., 2009. Assessing the root 694 of bilaterian animals with scalable phylogenomic methods. Proc Royal Soc Series B $695276,4261-4270$.

696 Hejnol, A., Pang, K., 2016. Xenacoelomorpha's significance for understanding 697 bilaterian evolution. Curr Opin Genet Dev 39, 48-54.

698 Hejnol, A., Rentzsch, F., 2015. Neural nets. Curr Biol 25, R782-786.

699 Hejnol, A., Schnabel, R., 2005. The eutardigrade Thulinia stephaniae has an 700 indeterminate development and the potential to regulate early blastomere ablations.

701 Development 132, 1349-1361.

702 Hejnol, A., Schnabel, R., 2006. What a couple of dimensions can do for you:

703 Comparative developmental studies using 4D-microscopy - examples from tardigrade 704 development. Integ Comp Biol 46, 151-161. 
705 Henry, J.J., Martindale, M.Q., 1998. Conservation of the spiralian developmental

706 program: cell lineage of the nemertean, Cerebratulus lacteus. Dev Biol 201, 253-269.

707 Henry, J.J., Martindale, M.Q., 1999. Conservation and innovation in spiralian

708 development. Hydrobiologia 402, 255-265.

709 Henry, J.Q., 2014. Spiralian model systems. Int J Dev Biol 58, 389-401.

710 Henry, J.Q., Martindale, M.Q., Boyer, B.C., 2000. The unique developmental program

711 of the acoel flatworm, Neochildia fusca. Developmental Biology 220, 285-295.

712 Hiebert, L.S., Maslakova, S.A., 2015. Expression of Hox, Cdx, and Six 3/6 genes in the

713 hoplonemertean Pantinonemertes californiensis offers insight into the evolution of

714 maximally indirect development in the phylum Nemertea. Evodevo 6, 26.

715 Hirth, F., Kammermeier, L., Frei, E., Walldorf, U., Noll, M., Reichert, H., 2003. An

716 urbilaterian origin of the tripartite brain: developmental genetic insights from

717 Drosophila. Development 130, 2365-2373.

718 Holland, L.Z., 2015. Evolution of basal deuterostome nervous systems. J Exp Biol 218, $719 \quad 637-645$.

720 Holland, L.Z., Carvalho, J.E., Escriva, H., Laudet, V., Schubert, M., Shimeld, S.M., Yu,

721 J.K., 2013. Evolution of bilaterian central nervous systems: a single origin? Evodevo 4, 72227.

723 Holland, L.Z., Venkatesh, T.V., Gorlin, A., Bodmer, R., Holland, N.D., 1998.

724 Characterization and developmental expression of AmphiNk2-2, an NK2 class

725 homeobox gene from Amphioxus. (Phylum Chordata; Subphylum Cephalochordata).

726 Dev Genes Evol 208, 100-105.

727 Holland, N.D., 2003. Early central nervous system evolution: an era of skin brains? Nat 728 Rev Neurosci 4, 617-627. 
729 Hubrecht, A.A.W., 1883. On the ancestral forms of the Chordata. Quart J Microsc Sci $730 \quad 23,349-368$.

731 Hubrecht, A.A.W., 1887. The relation of the Nemertea to the Vertebrata. Quart J

732 Microsc Sci 27, 605-644.

733 Hunnekuhl, V.S., Akam, M., 2014. An anterior medial cell population with an apical-

734 organ-like transcriptional profile that pioneers the central nervous system in the

735 centipede Strigamia maritima. Dev Biol 396, 136-149.

736 Janssen, R., 2017. Comparative analysis of gene expression patterns in the arthropod

737 labrum and the onychophoran frontal appendages, and its implications for the arthropod 738 head problem. Evodevo 8, 1.

739 Janssen, R., Budd, G.E., 2017. Investigation of endoderm marker-genes during 740 gastrulation and gut-development in the velvet worm Euperipatoides kanangrensis. Dev 741 Biol 427, 155-164.

742 Janssen, R., Jorgensen, M., Lagebro, L., Budd, G.E., 2015. Fate and nature of the

743 onychophoran mouth-anus furrow and its contribution to the blastopore. Proceedings.

744 Biological sciences / The Royal Society 282.

745 Jekely, G., Paps, J., Nielsen, C., 2015. The phylogenetic position of ctenophores and the 746 origin(s) of nervous systems. Evodevo 6, 1.

747 Jensen, D.D., 1963. Hoplonemertines, Myxinoids, and Vetebrate Origins, in:

748 Dougherty, E. (Ed.), The Lower Metazoa. University of California, Berkeley.

749 Kaul-Strehlow, S., Urata, M., Praher, D., Wanninger, A., 2017. Neuronal patterning of 750 the tubular collar cord is highly conserved among enteropneusts but dissimilar to the 751 chordate neural tube. Sci Rep 7, 7003. 
752 Kocot, K.M., Struck, T.H., Merkel, J., Waits, D.S., Todt, C., Brannock, P.M., Weese,

753 D.A., Cannon, J.T., Moroz, L.L., Lieb, B., Halanych, K.M., 2016. Phylogenomics of

754 Lophotrochozoa with Consideration of Systematic Error. Syst Biol.

755 Laumer, C.E., Bekkouche, N., Kerbl, A., Goetz, F., Neves, R.C., Sorensen, M.V.,

756 Kristensen, R.M., Hejnol, A., Dunn, C.W., Giribet, G., Worsaae, K., 2015. Spiralian

757 phylogeny informs the evolution of microscopic lineages. Curr Biol 25, 2000-2006.

758 Liebeskind, B.J., Hillis, D.M., Zakon, H.H., Hofmann, H.A., 2016. Complex Homology

759 and the Evolution of Nervous Systems. Trends Ecol Evol 31, 127-135.

760 Lowe, C.J., Clarke, D.N., Medeiros, D.M., Rokhsar, D.S., Gerhart, J., 2015. The

761 deuterostome context of chordate origins. Nature 520, 456-465.

762 Lowe, C.J., Terasaki, M., Wu, M., Freeman, R.M., Jr., Runft, L., Kwan, K., Haigo, S.,

763 Aronowicz, J., Lander, E., Gruber, C., Smith, M., Kirschner, M., Gerhart, J., 2006.

764 Dorsoventral patterning in hemichordates: insights into early chordate evolution. PLoS

765 Biol 4, e291.

766 Lowe, C.J., Wu, M., Salic, A., Evans, L., Lander, E., Stange-Thomann, N., Gruber,

767 C.E., Gerhart, J., Kirschner, M., 2003. Anteroposterior patterning in hemichordates and

768 the origins of the chordate nervous system. Cell 113, 853-865.

769 Lumsden, A., Krumlauf, R., 1996. Patterning the vertebrate neuraxis. Science 274,

$770 \quad 1109-1115$.

771 Lyons, D.C., Perry, K.J., Henry, J.Q., 2015. Spiralian gastrulation: germ layer

772 formation, morphogenesis, and fate of the blastopore in the slipper snail Crepidula

773 fornicata. Evodevo 6, 24.

774 Mannini, L., Deri, P., Gremigni, V., Rossi, L., Salvetti, A., Batistoni, R., 2008. Two

$775 \mathrm{msh} / \mathrm{msx}$-related genes, Djmsh1 and Djmsh2, contribute to the early blastema growth

776 during planarian head regeneration. Int J Dev Biol 52, 943-952. 
777 Marlow, H., Tosches, M.A., Tomer, R., Steinmetz, P.R., Lauri, A., Larsson, T., Arendt,

778 D., 2014. Larval body patterning and apical organs are conserved in animal evolution.

779 BMC Biol 12, 7.

780 Martin-Duran, J.M., Janssen, R., Wennberg, S., Budd, G.E., Hejnol, A., 2012.

781 Deuterostomic development in the protostome Priapulus caudatus. Curr Biol 22, 21617822166.

783 Martin-Duran, J.M., Pang, K., Borve, A., Le, H.S., Furu, A., Cannon, J.T., Jondelius,

784 U., Hejnol, A., 2018. Convergent evolution of bilaterian nerve cords. Nature 553, 45-50.

785 Martín-Durán, J.M., Passamaneck, Y.J., Martindale, M.Q., Hejnol, A., 2016. The

786 developmental basis for the recurrent evolution of deuterostomy and protostomy. Nature

787 Ecology \& Evolution 1, 0005.

788 Martín-Durán, J.M., Vellutini, B.C., Hejnol, A., 2015. Evolution and development of

789 the adelphophagic, intracapsular Schmidt's larva of the nemertean Lineus ruber.

790 Evodevo 6, 28.

791 Martin-Duran, J.M., Wolff, G.H., Strausfeld, N.J., Hejnol, A., 2016. The larval nervous 792 system of the penis worm Priapulus caudatus (Ecdysozoa). Philos Trans R Soc Lond B 793 Biol Sci 371, 20150050.

794 Martindale, M.Q., Hejnol, A., 2009. A developmental perspective: changes in the 795 position of the blastopore during bilaterian evolution. Dev Cell 17, 162-174.

796 Martindale, M.Q., Henry, J.Q., 1999. Intracellular fate mapping in a basal metazoan, the 797 ctenophore Mnemiopsis leidyi, reveals the origins of mesoderm and the existence of 798 indeterminate cell lineages. Dev Biol 214, 243-257.

799 Mayer, G., Whitington, P.M., 2009. Velvet worm development links myriapods with 800 chelicerates. Proceedings. Biological sciences / The Royal Society 276, 3571-3579. 
801 Meyer, N.P., Boyle, M.J., Martindale, M.Q., Seaver, E.C., 2010. A comprehensive fate

802 map by intracellular injection of identified blastomeres in the marine polychaete

803 Capitella teleta. Evodevo 1, 8.

804 Meyer, N.P., Seaver, E.C., 2010. Cell Lineage and Fate Map of the Primary

805 Somatoblast of the Polychaete Annelid Capitella teleta. Integ Comp Biol 50, 756-767.

806 Moroz, L.L., Kocot, K.M., Citarella, M.R., Dosung, S., Norekian, T.P., Povolotskaya,

807 I.S., Grigorenko, A.P., Dailey, C., Berezikov, E., Buckley, K.M., Ptitsyn, A., Reshetov,

808 D., Mukherjee, K., Moroz, T.P., Bobkova, Y., Yu, F., Kapitonov, V.V., Jurka, J.,

809 Bobkov, Y.V., Swore, J.J., Girardo, D.O., Fodor, A., Gusev, F., Sanford, R., Bruders,

810 R., Kittler, E., Mills, C.E., Rast, J.P., Derelle, R., Solovyev, V.V., Kondrashov, F.A.,

811 Swalla, B.J., Sweedler, J.V., Rogaev, E.I., Halanych, K.M., Kohn, A.B., 2014. The

812 ctenophore genome and the evolutionary origins of neural systems. Nature 510, 109-

813114

814 Nakanishi, N., Renfer, E., Technau, U., Rentzsch, F., 2012. Nervous systems of the sea

815 anemone Nematostella vectensis are generated by ectoderm and endoderm and shaped

816 by distinct mechanisms. Development 139, 347-357.

817 Nederbragt, A.J., te Welscher, P., van den Driesche, S., van Loon, A.E., Dictus, W.J., 818 2002. Novel and conserved roles for orthodenticle/ otx and orthopedia/ otp orthologs in

819 the gastropod mollusc Patella vulgata. Dev Genes Evol 212, 330-337.

820 Nicol, D., Meinertzhagen, I.A., 1988. Development of the central nervous system of the 821 larva of the ascidian, Ciona intestinalis L. I. The early lineages of the neural plate. Dev 822 Biol 130, 721-736.

823 Nishida, H., 1987. Cell lineage analysis in ascidian embryos by intracellular injection of 824 a tracer enzyme. III. Up to the tissue restricted stage. Dev Biol 121, 526-541. 
825 Norekian, T.P., Moroz, L.L., 2016. Development of neuromuscular organization in the 826 ctenophore Pleurobrachia bachei. J Comp Neurol 524, 136-151.

827 Northcutt, R.G., 2012. Evolution of centralized nervous systems: Two schools of

828 evolutionary thought. Proc Natl Acad Sci U S A 109 Suppl 1, 10626-10633.

829 Okkema, P.G., Ha, E., Haun, C., Chen, W., Fire, A., 1997. The Caenorhabditis elegans 830 NK-2 homeobox gene ceh-22 activates pharyngeal muscle gene expression in 831 combination with pha-1 and is required for normal pharyngeal development.

832 Development 124, 3965-3973.

833 Pang, K., Martindale, M.Q., 2008. Developmental expression of homeobox genes in the 834 ctenophore Mnemiopsis leidyi. Dev Genes Evol 218, 307-319.

835 Pani, A.M., Mullarkey, E.E., Aronowicz, J., Assimacopoulos, S., Grove, E.A., Lowe, 836 C.J., 2012. Ancient deuterostome origins of vertebrate brain signalling centres. Nature $837483,289-294$.

838 Puelles, L., 2013. Plan of the Developing Vertebrate Nervous System, in: Rubenstein, 839 J.L., Rakic, P. (Eds.), Patterning and Cell Type Specification in the Developing CNS 840 and PNS. Academic Press, Amsterdam, pp. 187-209.

841 Puelles, L., Ferran, J.L., 2012. Concept of neural genoarchitecture and its genomic 842 fundament. Front Neuroanat 6, 47.

843 Raikova, O.I., Meyer-Wachsmuth, I., Jondelius, U., 2016. The plastic nervous system of 844 Nemertodermatida. Org Divers Evol 16, 85-104.

845 Range, R., 2014. Specification and positioning of the anterior neuroectoderm in 846 deuterostome embryos. Genesis 52, 222-234.

847 Reisinger, E., 1925. Untersuchungen am Nervensystem der Bothrioplana semperi 848 Braun. Zeitschr Morph Ökol Tiere 5, 119-149. 
849 Reisinger, E., 1971. Die Evolution des Orthogons der Spiralier und das

850 Archicölomatenproblem. Z. zool. Syst. Evolut.-forsch. 10, 1-43.

851 Remane, A., 1952. Die Grundlagen des natürlichen Systems, der vergleichenden

852 Anatomie und der Phylogenie. Akademische Verlagsgesellschaft Geest \& Portig K.-G., 853 Leipzig.

854 Richards, G.S., Rentzsch, F., 2014. Transgenic analysis of a SoxB gene reveals neural 855 progenitor cells in the cnidarian Nematostella vectensis. Development 141, 4681-4689. 856 Richter, S., Loesel, R., Purschke, G., Schmidt-Rhaesa, A., Scholtz, G., Stach, T., Vogt, 857 L., Wanninger, A., Brenneis, G., Döring, C., Faller, S., Fritsch, M., Grobe, P., Heuer, 858 C.M., Kaul, S., Møller, O.S., Müller, C.H.G., Rieger, V., Rothe, B.H., Stegner, M.E.J., 859 Harzsch, S., 2010. Invertebrate neurophylogeny: suggested terms and definitions for a 860 neuroanatomical glossary. Front Zool 7, 29.

861 Ristoratore, F., Spagnuolo, A., Aniello, F., Branno, M., Fabbrini, F., Di Lauro, R., 1999.

862 Expression and functional analysis of Cititfl, an ascidian $N K-2$ class gene, suggest its 863 role in endoderm development. Development 126, 5149-5159.

864 Ruiz-Trillo, I., Riutort, M., Littlewood, D.T.J., Herniou, E.A., Baguña, J., 1999. Acoel 865 flatworms: earliest extant bilaterian Metazoans, not members of Platyhelminthes. 866 Science 283, 1919-1923.

867 Ryan, J.F., 2014. Did the ctenophore nervous system evolve independently? Zoology $868117,225-226$.

869 Ryan, J.F., Pang, K., Schnitzler, C.E., Nguyen, A.D., Moreland, R.T., Simmons, D.K., 870 Koch, B.J., Francis, W.R., Havlak, P., Program, N.C.S., Smith, S.A., Putnam, N.H., 871 Haddock, S.H., Dunn, C.W., Wolfsberg, T.G., Mullikin, J.C., Martindale, M.Q., 872 Baxevanis, A.D., 2013. The genome of the ctenophore Mnemiopsis leidyi and its 873 implications for cell type evolution. Science 342, 1242592. 
874 Santagata, S., 2011. Evaluating neurophylogenetic patterns in the larval nervous

875 systems of brachiopods and their evolutionary significance to other bilaterian phyla. J

876 Morphol 272, 1153-1169.

877 Santagata, S., Resh, C., Hejnol, A., Martindale, M.Q., Passamaneck, Y.J., 2012.

878 Development of the larval anterior neurogenic domains of Terebratalia transversa

879 (Brachiopoda) provides insights into the diversification of larval apical organs and the 880 spiralian nervous system. Evodevo 3, 3.

881 Schiemann, S.M., Martin-Duran, J.M., Borve, A., Vellutini, B.C., Passamaneck, Y.J., 882 Hejnol, A., 2017. Clustered brachiopod Hox genes are not expressed collinearly and are 883 associated with lophotrochozoan novelties. Proc Natl Acad Sci U S A 114, E1913884 E1922.

885 Schmidt-Rhaesa, A., 2007. The evolution of organ systems. Oxford University Press. 886 Schmidt-Rhaesa, A., Harzsch, S., Purschke, G., 2016. Structure \& Evolution of 887 Invertebrate Nervous Systems. Oxford University Press, Oxford.

888 Schnitzler, C.E., Simmons, D.K., Pang, K., Martindale, M.Q., Baxevanis, A.D., 2014. 889 Expression of multiple Sox genes through embryonic development in the ctenophore 890 Mnemiopsis leidyi is spatially restricted to zones of cell proliferation. Evodevo 5, 15. 891 Sebé-Pedrós, A., Chomsky, E., Pang, K., Lara-Astiaso, D., Gaiti, F., Mukamel, Z., 892 Amit, I., Hejnol, A., Degnan, B., Tanay, A., 2018. Early metazoan cell type diversity 893 and the evolution of multicellular gene regulation. Nat Eco Evol.

894 Sedgwick, A., 1884. On the origin of metameric segmentation and some other 895 morphological questions. Quart J Microsc Sci 24, 43-82.

896 Sedgwick, A., 1884-1885. The development of Peripatus capensis. Proc Royal Soc 897 Series B 38, 354-361. 
899 phylogenomic studies can be driven by a handful of genes. Nat Eco Evol 1, 0126.

900 Shimeld, S.M., Holland, N.D., 2005. Amphioxus molecular biology: insights into

901 vertebrate evolution and developmental mechanisms. Canadian Journal of Zoology 83, $90290-100$.

903 Simion, P., Philippe, H., Baurain, D., Jager, M., Richter, D.J., Di Franco, A., Roure, B., 904 Satoh, N., Queinnec, E., Ereskovsky, A., Lapebie, P., Corre, E., Delsuc, F., King, N., 905 Worheide, G., Manuel, M., 2017. A Large and Consistent Phylogenomic Dataset 906 Supports Sponges as the Sister Group to All Other Animals. Curr Biol 27, 958-967.

907 Simmons, D.K., Pang, K., Martindale, M.Q., 2012. Lim homeobox genes in the 908 Ctenophore Mnemiopsis leidyi: the evolution of neural cell type specification. Evodevo $9093,2$.

910 Sinigaglia, C., Busengdal, H., Leclere, L., Technau, U., Rentzsch, F., 2013. The 911 bilaterian head patterning gene six $3 / 6$ controls aboral domain development in a 912 cnidarian. PLoS Biol 11, e1001488.

913 Steinböck, O., 1966. Die Hofsteniiden (Turbellaria acoela). Z. zool. Syst. Evolutionsf. $914 \quad 4,58-195$.

915 Steinmetz, P.R.H., Kostyuchenko, R.P., Fischer, A., Arendt, D., 2011. The segmental 916 pattern of otx, gbx, and Hox genes in the annelid Platynereis dumerilii. Evol Dev 13, $917 \quad 72-79$.

918 Stolfi, A., Levine, M., 2011. Neuronal subtype specification in the spinal cord of a 919 protovertebrate. Development 138, 995-1004.

920 Stollewerk, A., Chipman, A.D., 2006. Neurogenesis in myriapods and chelicerates and 921 its importance for understanding arthropod relationships. Integrative and comparative 922 biology 46, 195-206. 
923 Strausfeld, N.J., Hirth, F., 2013. Deep homology of arthropod central complex and 924 vertebrate basal ganglia. Science 340, 157-161.

925 Struck, T.H., Wey-Fabrizius, A.R., Golombek, A., Hering, L., Weigert, A., Bleidorn,

926 C., Klebow, S., Iakovenko, N., Hausdorf, B., Petersen, M., Kuck, P., Herlyn, H.,

927 Hankeln, T., 2014. Platyzoan paraphyly based on phylogenomic data supports a

928 noncoelomate ancestry of spiralia. Mol Biol Evol 31, 1833-1849.

929 Sulston, J.E., Schierenberg, E., White, J.G., Thomson, J.N., 1983. The embryonic cell

930 lineage of the nematode Caenorhabditis elegans. Developmental Biology 100, 64-119.

931 Tessmar-Raible, K., Raible, F., Christodoulou, F., Guy, K., Rembold, M., Hausen, H.,

932 Arendt, D., 2007. Conserved sensory-neurosecretory cell types in annelid and fish

933 forebrain: insights into hypothalamus evolution. Cell 129, 1389-1400.

934 Tomer, R., Denes, A.S., Tessmar-Raible, K., Arendt, D., 2010. Profiling by image

935 registration reveals common origin of annelid mushroom bodies and vertebrate pallium.

936 Cell 142, 800-809.

937 Tosches, M.A., Arendt, D., 2013. The bilaterian forebrain: an evolutionary chimaera.

938 Curr Opin Neurobiol 23, 1080-1089.

939 Vellutini, B.C., Hejnol, A., 2016. Expression of segment polarity genes in brachiopods

940 supports a non-segmental ancestral role of engrailed for bilaterians. Sci Rep 6, 32387.

941 Vellutini, B.C., Martin-Duran, J.M., Hejnol, A., 2017. Cleavage modification did not

942 alter blastomere fates during bryozoan evolution. BMC Biol 15, 33.

943 Vermeren, M., Keynes, R., 2001. Vertebrate Central Nervous System: Pattern

944 Formation, eLS. John Wiley \& Sons, Ltd.

945 von Baer, K.E., 1834. Die Metamorphose des Eies der Batrachier vor der Erscheinung

946 des Embryo und Folgerungen aus ihr für die Theorie der Erzeugung. Müller's Arch

947 Anat Physiol wiss Med, 481-508. 
948 Wei, Z., Angerer, R.C., Angerer, L.M., 2011. Direct development of neurons within

949 foregut endoderm of sea urchin embryos. Proc Natl Acad Sci U S A 108, 9143-9147.

950 Whelan, N.V., Kocot, K.M., Moroz, L.L., Halanych, K.M., 2015. Error, signal, and the

951 placement of Ctenophora sister to all other animals. Proc Natl Acad Sci U S A 112,

$952 \quad 5773-5778$.

953 Whitington, P.M., 1996. Evolution of neural development in the arthropods. Semin Cell

954 Dev Biol 7, 605-614.

955 Winterbottom, E.F., Illes, J.C., Faas, L., Isaacs, H.V., 2010. Conserved and novel roles

956 for the Gsh2 transcription factor in primary neurogenesis. Development 137, 2623-

9572631.

958 Wolff, G.H., Strausfeld, N.J., 2015. Genealogical correspondence of mushroom bodies

959 across invertebrate phyla. Curr Biol 25, 38-44.

960 Wollesen, T., Rodríguez Monje, S.V., Todt, C., Degnan, B.M., Wanninger, A., 2015.

961 Ancestral role of Pax2/5/8 in molluscan brain and multimodal sensory system

962 development. BMC Evol Biol 15.

963 Yao, Y., Minor, P.J., Zhao, Y.T., Jeong, Y., Pani, A.M., King, A.N., Symmons, O.,

964 Gan, L., Cardoso, W.V., Spitz, F., Lowe, C.J., Epstein, D.J., 2016. Cis-regulatory

965 architecture of a brain signaling center predates the origin of chordates. Nat Genet 48 ,

$966 \quad 575-580$.

967 


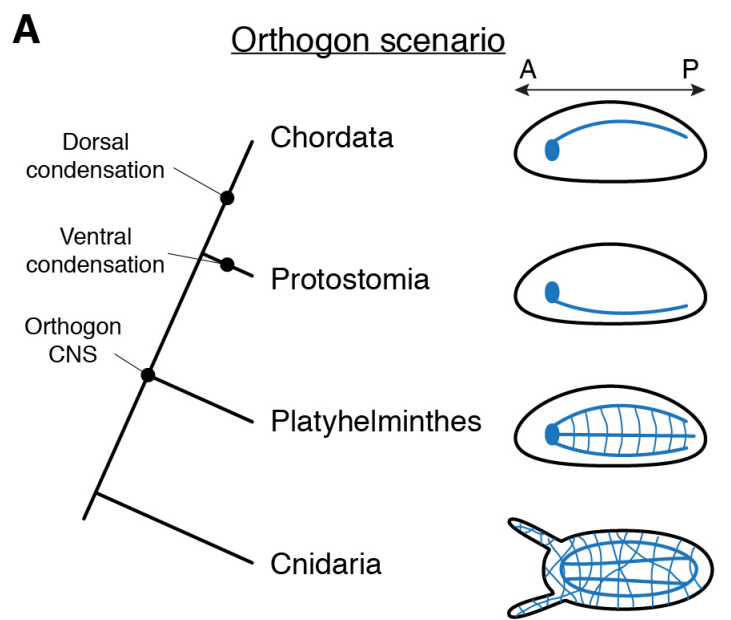

B 'Oral nerve ring' scenario

C

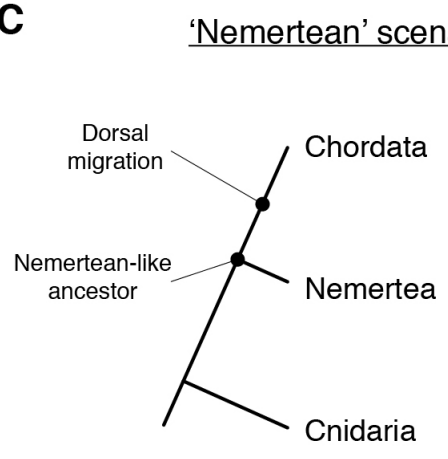

969

970

971

972

973

974 The 'oral nerve ring' scenario explains the evolution of ventral paired nerve cords by

975 the elongation and fusion in the middle of the oral nerve ring condensation of extant sea

\section{Figure 1. Traditional scenarios for the evolution of a centralized nervous system.}

(A) In the orthogon scenario, the ancestral bilaterian was a flatworm-like animal with an orthogonal arrangement of the nervous system. Dorsal and ventral nerve cords evolved by the subsequent loss of ventral and dorsal nerves of the orthogon, respectively. (B)
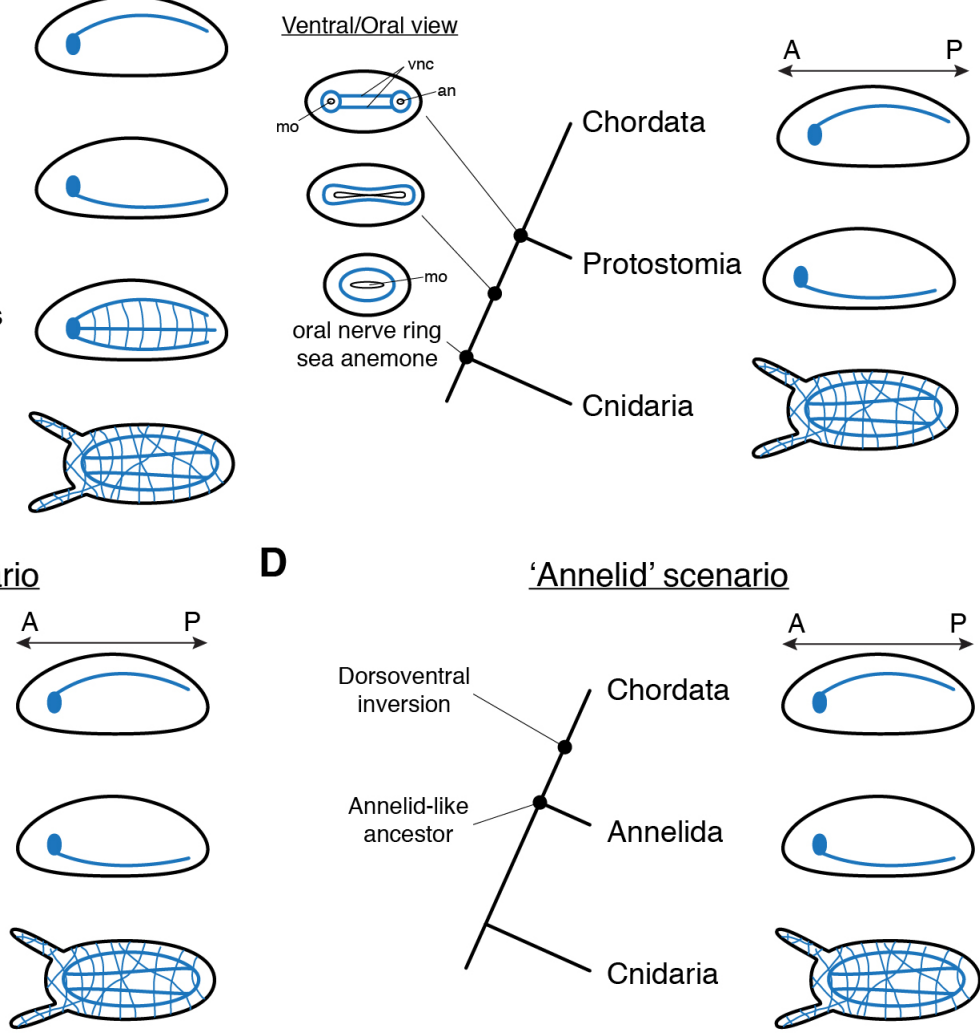

D

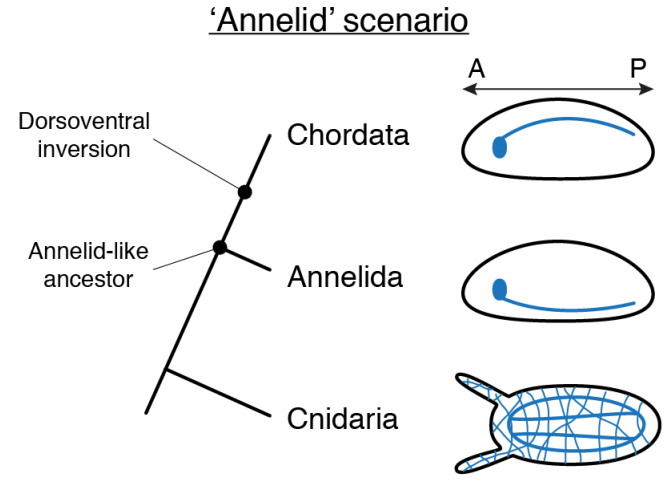
anemones. (C) In the nemertean scenario, the evolution of the chordate CNS occurs

977 from a nemertean-like ancestor, by movement to the dorsal side of the ventrolateral

978 nerve cords. (D) In the annelid scenario, the chordate CNS evolves from an annelid-like

979 ancestor that flips over its dorsoventral axis. Drawings are not to scale, and the CNS is

980 in blue. See main text for references. An, anus; mo, mouth; vnc, ventral nerve cords. 


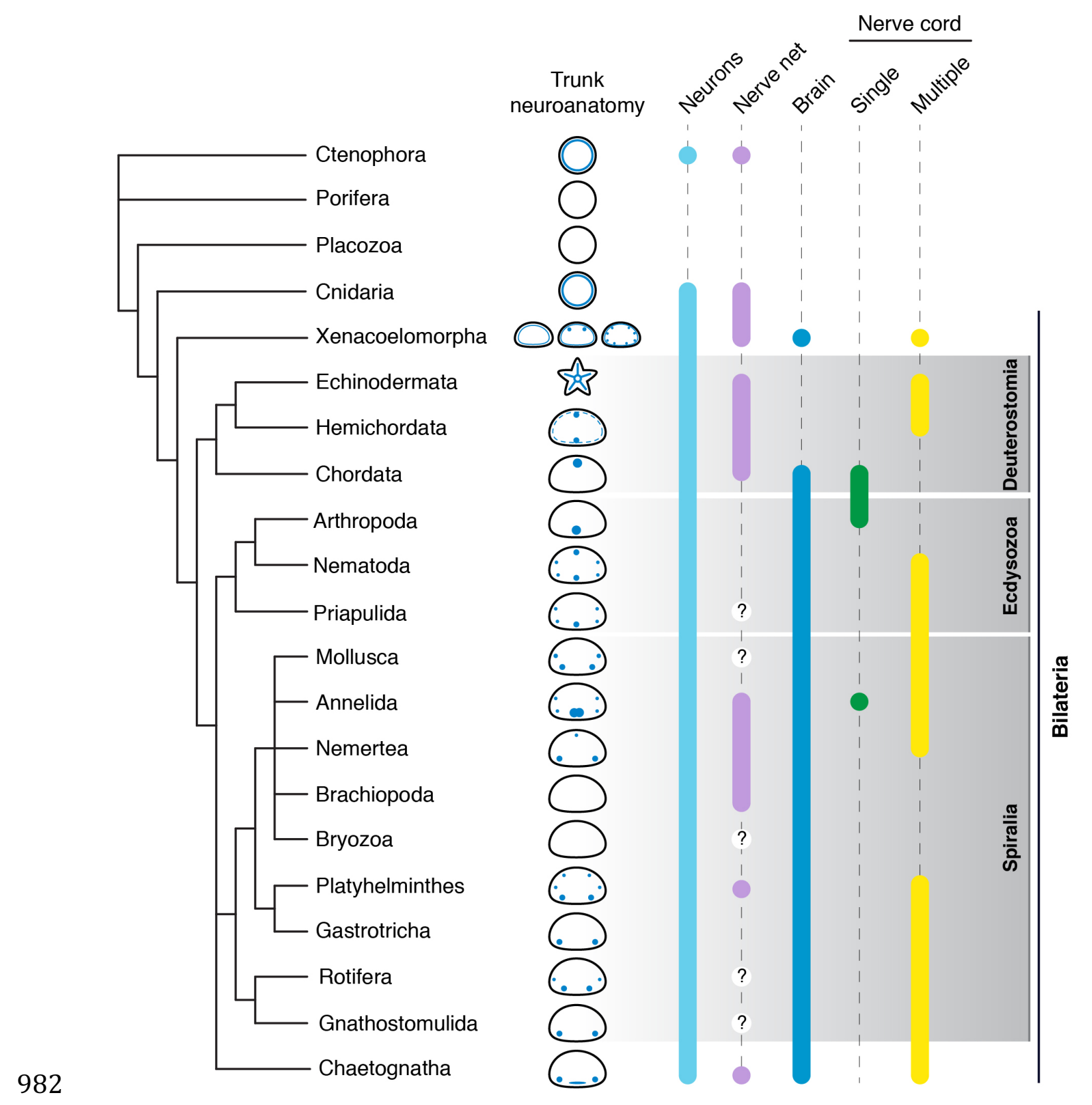

983 Figure 2. The diversity of neural anatomies in Metazoa. Distribution of

984 neuroanatomical characters in representative metazoan lineages under the current

985 phylogenetic relationships supported by molecular data (Dunn et al., 2014).

986 Neuroanatomy is based on (Schmidt-Rhaesa, 2007). 
A

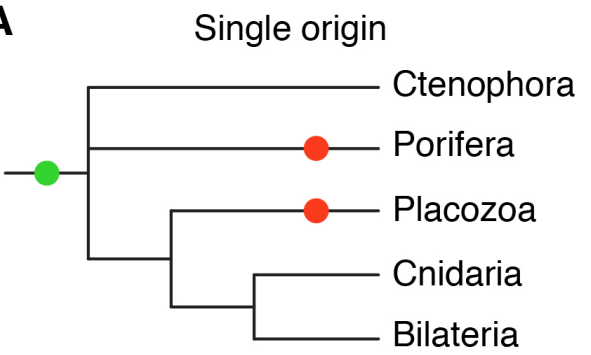

B $\quad$ Multiple origin

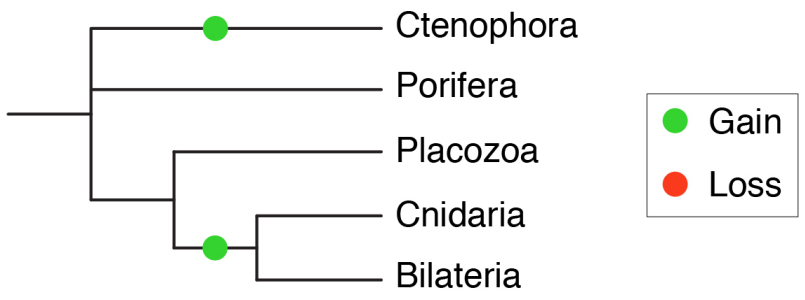

989 Figure 3. The evolution of the nervous system. Possible evolutionary scenarios for the

990 evolution of neurons and a nervous system in Metazoa given the current position of

991 Ctenophora. (A) If ctenophore, cnidarian and bilaterian nervous systems are

992 homologous, neurons got independently lost in sponges and placozoans. (B)

993 Alternatively, the nervous systems of ctenophores and cnidarians+bilaterians evolved

994 convergently. 


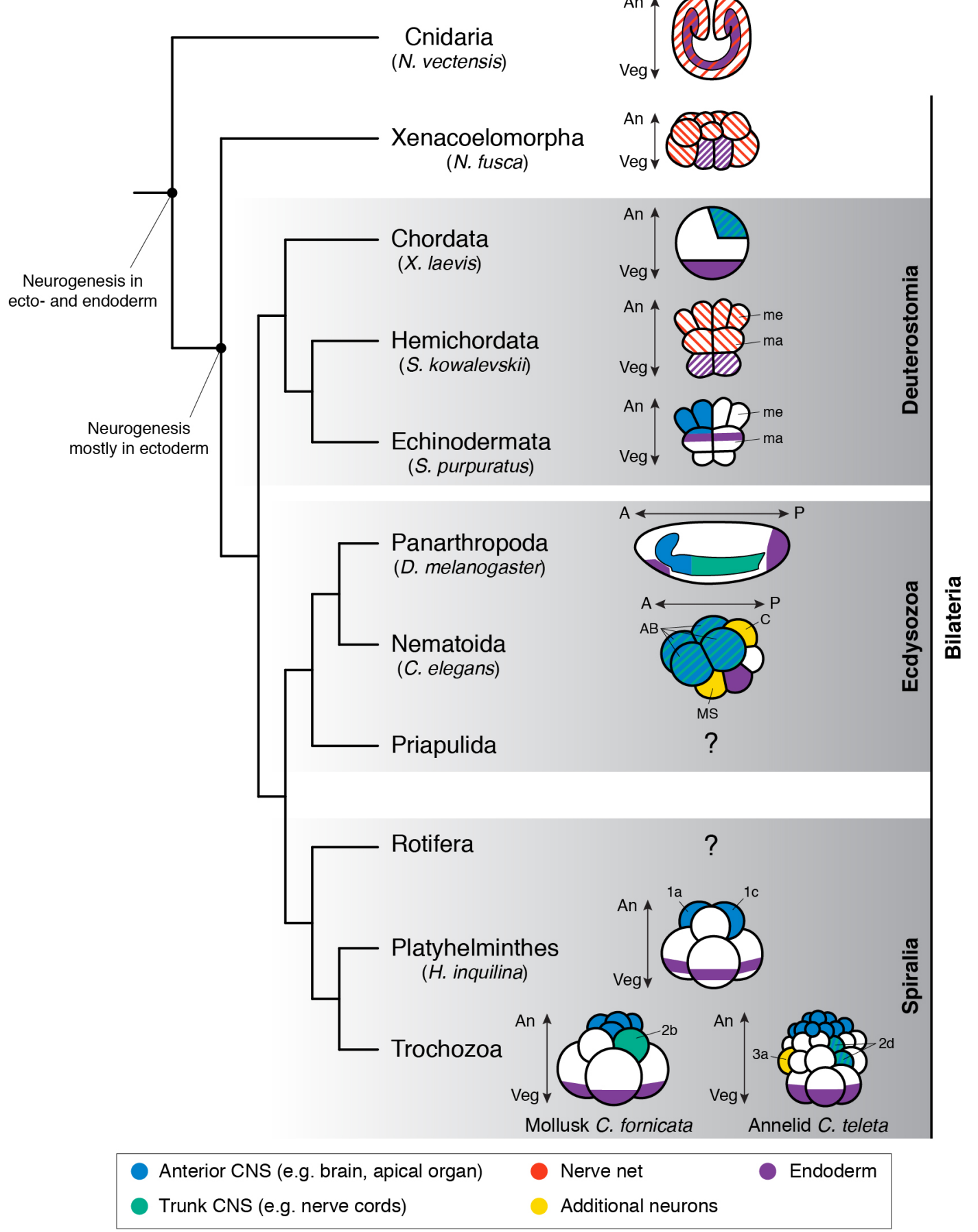

997 Figure 4. The diversity of neuroectodermal fate maps in Bilateria. Schematic fate

998 maps of representatives of the major bilaterian lineages and cnidarians, with special

999 emphasis on the origin of the nervous system and endoderm. In the cnidarian $N$.

1000 vectensis, the neurons that form the diffuse nerve net (red lines) develop from both the

1001 ectoderm and endoderm (purple). In Bilateria, the vast majority of neurons develop 
1002 separate from the endoderm. The mode of specification and spatial position of neuronal

1003 progenitors is variable in Bilateria, even among lineages that share a common

1004 developmental program, such as spiral cleaving embryos (Trochozoa). Drawings are not

1005 to scale. Ma, macromeres; me, mesomeres.

1006 


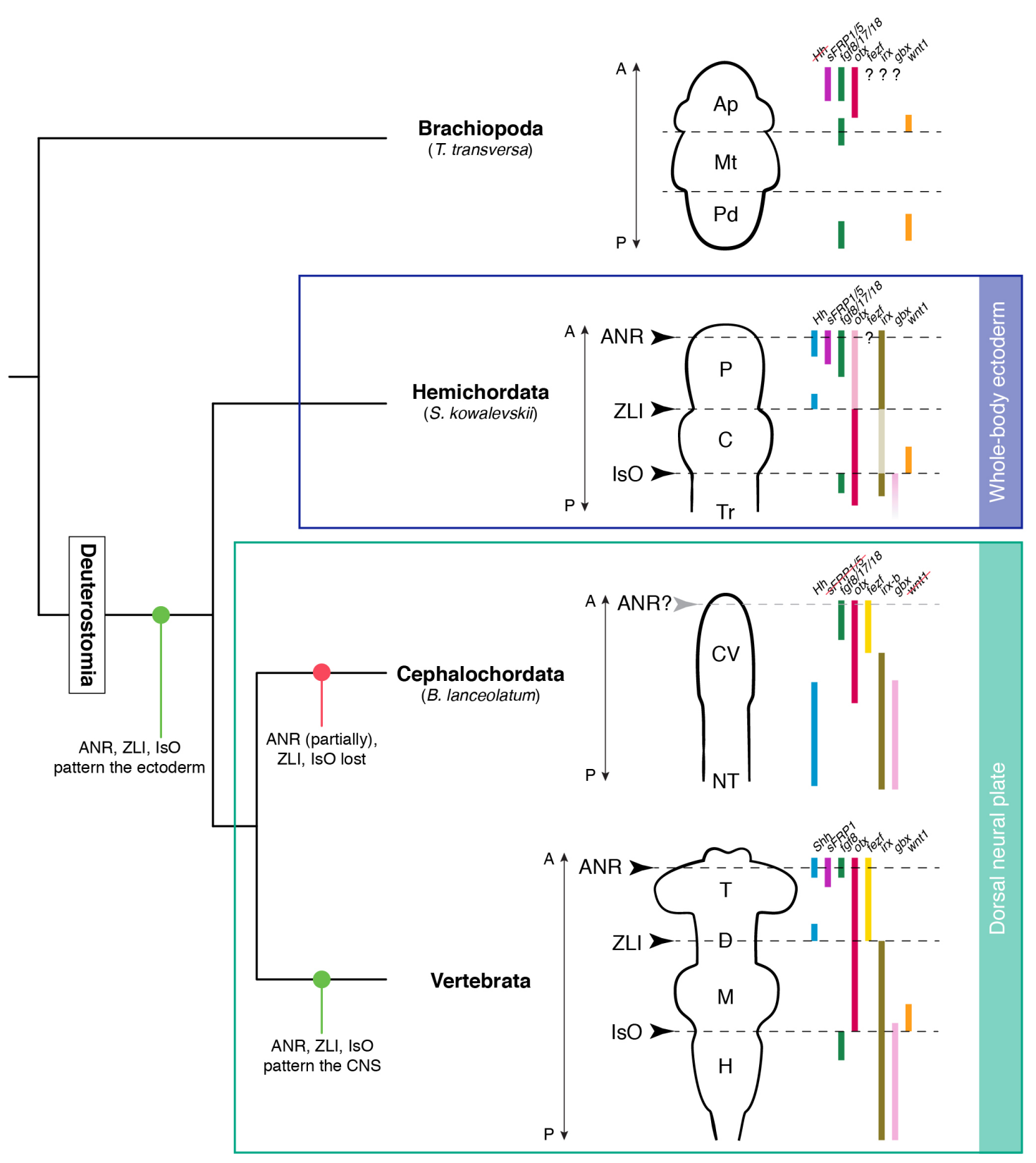

Figure 5. The evolution of anteroposterior neuronal patterning in Deuterostomia.

1009 Schematic representation of the anteroposterior expression domains of genes involved

1010 in patterning the vertebrate CNS and defining the major brain signaling centers in

1011 brachiopods (outgroup), hemichordates, cephalochordates, and vertebrates. The

1012 similarities in expression patterns and functional interrelationships of these genes

1013 between hemichordates and vertebrates suggest that the anterior neural ridge (ANR), the

1014 zona limitans intrathalamica (ZLI) and the isthmic organizer (IsO) are conserved

1015 deuterostomian signaling centers involved in general ectodermal patterning. These 
1016 organizers were partially lost in cephalochordates and urochordates, and coopoted into

1017 neuroectodermal/brain patterning in vertebrates. Drawings are not to scale. Question

1018 marks indicate unknown expression and red crossed text indicates that gene expression

1019 is not related to the ectoderm and/or the nervous system. See main text for references.

1020 Ap, apical lobe; C, collar; CV, cerebral vesicle; D, diencephalon; H, hindbrain; M,

1021 midbrain; Mt, mantle lobe; NT, neural tube; P, proboscis; Pd, pedicle lobe; T,

1022 telencephalon; Tr, trunk.

1023 


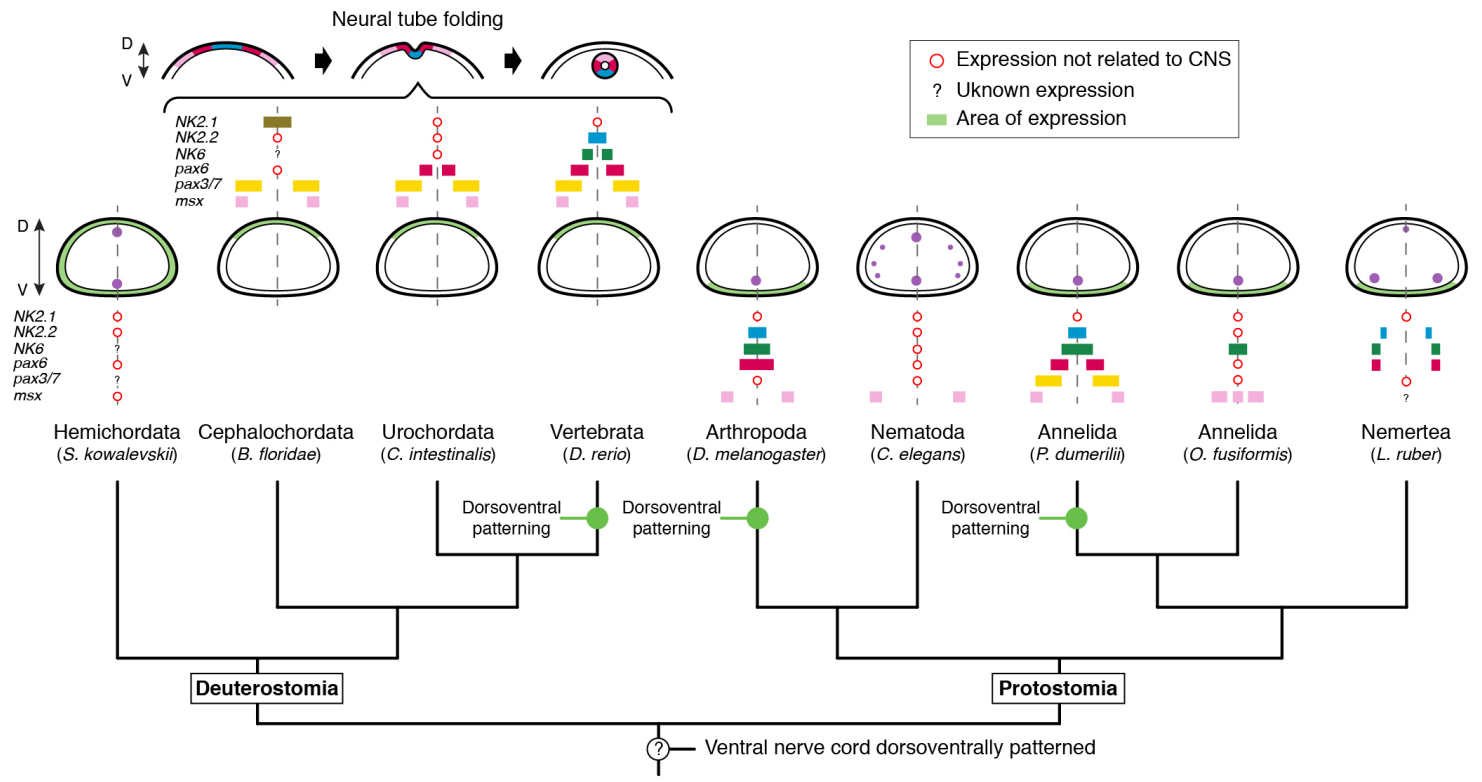

1025 Figure 6. The evolution of dorsoventral nerve cord patterning in Bilateria. The

1026 genes $N K 2.1, N K 2.2, N K 6, \operatorname{pax} 6, \operatorname{pax} 3 / 7$, and $m s x$ exhibit a similar combinatorial

1027 expression along the dorsoventral axis of vertebrates, arthropods, and the annelid $P$.

1028 dumerilii. This combinatorial expression is associated with the molecular patterning of

1029 the medially condensed nerve cord of these three bilaterian lineages and has been

1030 argued to support the presence of a single ventral nerve cord in the last common

1031 ancestor of Protostomia and Deuterostomia. However, a similar dorsoventral expression

1032 of these genes is absent in hemichordates, nematodes, and many spiralian taxa, such as

1033 the nemertean L. ruber and the annelid O. fusiformis, which similar to P. dumerilii, also

1034 shows a medially condensed unpaired nerve cord. Similarly, cephalochordates and

1035 urochordates, which do have a single dorsal nerve cord, do not exhibit the dorsoventral

1036 nerve cord patterning of vertebrates. These data favors more parsimonious scenarios

1037 that propose that the similarities in molecular patterning between vertebrates,

1038 Drosophila and the annelid P. dumerilii evolved by convergence. 